\title{
Numerical Research and Parametric Study on the Thermal Performance of a Vertical Earth-to-Air Heat Exchanger System
}

\author{
Zhening Zhang, ${ }^{1,2}$ Jindong Sun $\mathbb{C D}^{1,2}$ Zhenxing Zhang, ${ }^{1,2}$ Xinxin Jia, ${ }^{1,2}$ and Yang Liu ${ }^{1,2}$ \\ ${ }^{1}$ School of Environmental and Energy Engineering, Beijing University of Civil Engineering and Architecture, \\ Beijing 100044, China \\ ${ }^{2}$ Building Environment and Energy Power Engineering Experimental Center, \\ Beijing University of Civil Engineering and Architecture, Beijing 100044, China \\ Correspondence should be addressed to Jindong Sun; sunjindong@bucea.edu.cn
}

Received 26 February 2021; Revised 7 June 2021; Accepted 15 July 2021; Published 23 July 2021

Academic Editor: Luis M. López-Ochoa

Copyright $\odot 2021$ Zhening Zhang et al. This is an open access article distributed under the Creative Commons Attribution License, which permits unrestricted use, distribution, and reproduction in any medium, provided the original work is properly cited.

\begin{abstract}
The earth-to-air heat exchanger (EAHE) system, as a clean and efficient shallow geothermal energy application technology, has obvious effects in reducing the energy consumption of passive low-energy buildings. The traditional horizontal EAHE system is difficult to apply and popularize due to its large occupation, unfavorable shallow soil temperature, and difficulty in timely centralized discharge of condensed water. This paper proposes a new type of vertical earth-to-air heat exchanger (VEAHE) system. The VEAHE system has a number of advantages such as smaller occupation, efficient geothermal energy utilization, and centralized discharge of condensed water. In order to evaluate the influence of different parameters on the thermal performance of the VEAHE system, a mathematical model of the VEAHE system was developed. And, the data calculated by the model highly tallied with the experimental data. The results showed that laying thermal insulation layers at the outlet of risers will effectively restrain the interference of downcomers to risers. It is advisable to set thickness and length of the insulation layer at $30 \mathrm{~mm}$ and $3 \mathrm{~m}$. Considering the compromise between thermal performance and construction costs of the VEAHE system, the length of the ducts at $30-50 \mathrm{~m}$ and the diameter at $150-250 \mathrm{~mm}$ are recommended. The air supply volume of a single shaft can reach $500-1200 \mathrm{~m}^{3} / \mathrm{h}$ as the air velocity reaches $3-7 \mathrm{~m} / \mathrm{s}$.
\end{abstract}

\section{Introduction}

The increasing building energy consumption has imposed considerable energy burden and environmental pollution upon the society, which has severely restricted the sustainable development process of the world [1-3]. China's carbon-neutral development goal by 2060 has put forward strict constraints on building energy consumption. Due to its ultralow energy consumption, passive low-energy buildings have been developing rapidly in China [4]. In 2020 , the total area of passive low-energy buildings completed and under construction in China has exceeded 10 million square meters, and it is conservatively estimated that it will reach 2 billion square meters by 2035. An efficient fresh air system is the key to ensuring a comfortable indoor environment of passive buildings. How to reduce the energy consumption of the cooling and heating air load has become an important research direction in the field of passive lowenergy buildings. It is an important means to use the EAHE system to preheat and precool fresh air to reduce the cooling and heating load of fresh air.

The EAHE system is a ventilation and energy-saving measure that uses shallow soil to heat outdoor low-temperature air in winter (or cool outdoor high-temperature air in summer) [5-9]. Kaushal [10] points out that EAHE system can be an economic alternative to the traditional air conditioning system, and a well-designed EAHE system can reduce the electric power consumption of a building by at least 25-30\%. In addition, many teams have conducted research on the thermal performance of the EAHE system in different climate applications. For example, Yang et al. [11] found that if an EAHE system with a horizontal air duct 
length of $100 \mathrm{~m}$ and a radius of $0.5 \mathrm{~m}$ is built in a typical hotsummer and cold-winter area, it can reduce the outdoor air temperature by $7^{\circ} \mathrm{C}$ in summer and generate $3 \mathrm{~kW}$ of heating (or cooling) capacity in the transitional season; Ahmed et al. [12] built an EAHE system composed of 20 PVC air ducts of $21 \mathrm{~mm}$ diameter at the depth of $-2 \mathrm{~m}$, and it showed a result that a room covering $27.23 \mathrm{~m}^{2}$ could save up to $866.54 \mathrm{~kW}$ $(8.82 \%)$ of energy per year in a subtropical climate. And, under such climatic condition, the local thermal potential of soil temperature change can be reached at a relatively low depth, with its peak at $5^{\circ} \mathrm{C}[13]$; In arid areas, an EAHE system buried at $1.5 \mathrm{~m}$ underground with a duct length of $66 \mathrm{~m}$ and a diameter of $0.11 \mathrm{~m}$ can increase the relative humidity of outdoor air by $19 \%$, and dry air by $37.5 \%$ [14]. In order to further reduce building energy consumption, now EAHE systems are mostly combined with other heat exchange devices. Sakhri et al. [15, 16] studied the coupling characteristics of the EAHE system and the solar chimney; Congedo et al. [17] explored the thermal performance of the ASHP-EAHE system (air source heat pump-earth air heat exchanger system) under the different environmental factors. Li et al. [18] proposed to use the heat recovery unit (HRU) device to further heat exchange processing between the air heated by the EAEH system and the return air of indoor air.

However, due to the complex construction of the EAHE system and its high cost, researchers mostly focus on developing and optimizing mathematical models. Papakostas et al. [19] evaluated and modified the GAEA (Graphische Auslegung von Erdwärme Austauschern) model and the De Paepe-Janssens model; Minaei and Safikhani [20] used Laplace transform to derive and solve the control equations of air flow and the soil around the air ducts. It is proposed that ignoring the thermal saturation of the soil will lead to an increase in the thermal performance of the system; Su et al. [21] developed a sequential calculation method, based on an appropriate discrete scheme, for the air submodel and the soil submodel, respectively, with the one-dimensional implicit transient convection diffusion submodel; Kumar et al. $[22,23]$ developed artificial neural network and genetic algorithms to optimize the input variables of the EAHE system and evaluated the influences of various factors involved in the energy-balance equation about the buried depth of underair ducts through sensitivity analysis to analyze the "passive" heating and cooling performance of buildings. Rodrigues et al. and Amanowicz et al. [24, 25] used numerical simulation to study the influences of different layouts of horizontal ducts on the heat transfer performance of the EAHE system.

At present, the research on the EAHE system mainly focuses on horizontal air ducts of length mostly at 50-100 m and the buried depth at $2-5 \mathrm{~m}$ underground $[26,27]$. Data showed that the changes per day of the depth in surface temperature are no deeper than $0.5 \mathrm{~m}$, and short-term temperature changes fade at a depth of about $1 \mathrm{~m}$ underground. The thermal inertia of the soil will inhibit and delay the transmission of surface temperature fluctuations to the deep soil. As a result, the shallow soil temperature is affected by the surface temperature and will change with the external meteorological conditions, seasons, and surface conditions. Although the soil at this depth is relatively stable in a short term, it usually makes the soil temperature at this depth higher in summer and lower in winter [28]. Many researchers have studied on this subject. Belatrache et al. [29] found that, in some areas of Algeria, the soil temperature at a depth of $5 \mathrm{~m}$ fluctuates between $25^{\circ} \mathrm{C}$ and $28^{\circ} \mathrm{C}$ throughout the year. After applying the EAHE system to this soil depth, the lowest air outlet temperature during summer cooling is higher than $25^{\circ} \mathrm{C}$. When the depth of the buried pipes is less than $5 \mathrm{~m}$, the air outlet temperature of the system will increase as the soil temperature rises. In the Bhopal area of India, Soni et al. [30] found that, at the depth of $2.7 \mathrm{~m}$, the soil temperature is close to $30^{\circ} \mathrm{C}$. When the outdoor temperature fluctuates from 37.5 to $46^{\circ} \mathrm{C}$, the air temperature at the outlet of the EAHE system fluctuates between 35.5 and $42^{\circ} \mathrm{C}$. Obviously, applying the horizontal buried pipe EAHE system in an area with such a high soil temperature will result in a higher air temperature at the air outlet, so it will be difficult to meet the requirements of indoor air supply temperature in summer. However, as the buried depth of the air ducts increases, it will cause problems such as larger construction volume, higher costs, and a large amount of land occupation [31], which usually limit the application of the EAHE system in densely built areas $[28,32]$.

Therefore, this paper will be divided into three parts to solve the above problems. Firstly, a new type of vertical earth-to-air heat exchanger (VEAHE) system was proposed. The physical model and mathematical model of the VEAHE system were established at the same time. Secondly, through the experimental platform of the VEAHE system, the accuracy of the mathematical model of the VEAHE system was verified through the actual measurement of its heat transfer capacity. Finally, the thermal performance of the VEAHE system was numerically simulated and parameterized. The research results provided guidance and basis for its construction and application. The flowchart of the entire methodology is shown in Figure 1.

\section{The Description of the VEAHE System}

The VEAHE system is mainly composed of vertical shafts, downcomers, risers, condensate collection devices, and backfill soil, as shown in Figure 2. The downcomers, the risers, and the condensate collection devices constitute a vertical U-shaped air duct system, in which the diameters of downcomers and risers are the same. The vertical shafts provide the sinking space for the vertical U-shaped air duct system. After the vertical air duct system sinks to a certain position, the original soil is backfilled. The vertical shafts, to a certain extent, play a role in protecting the vertical air duct system. The condensate collection devices are used to collect the condensed water in summer, and excess condensed water is discharged by the pumps. The vertical shafts are made of reinforced concrete tubes. The downcomers and the risers can be made of stainless steel, ductile iron, PE, PVC, etc. The condensate collection devices can be made of stainless steel and PVC material. 


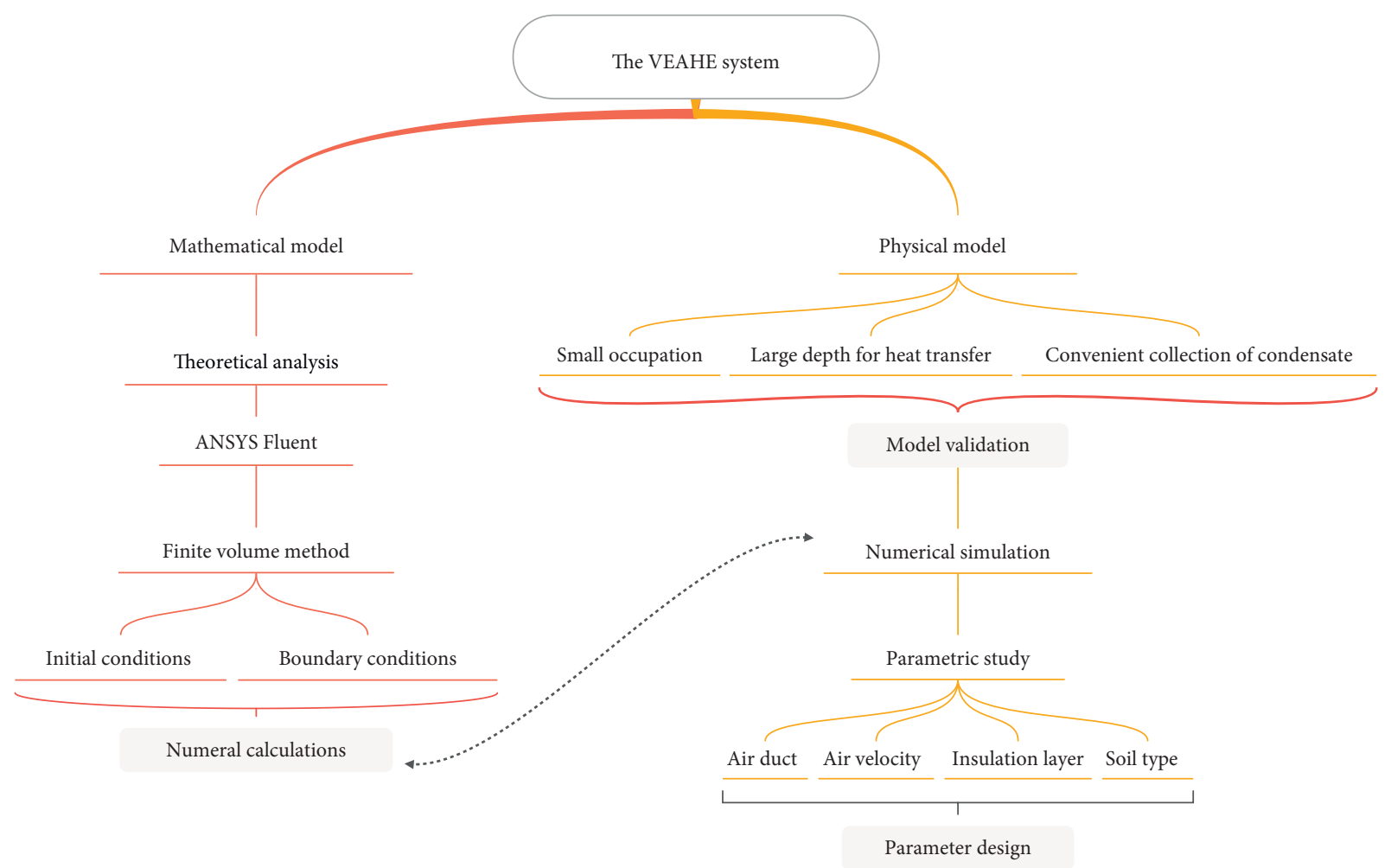

Figure 1: Flowchart of the entire methodology.

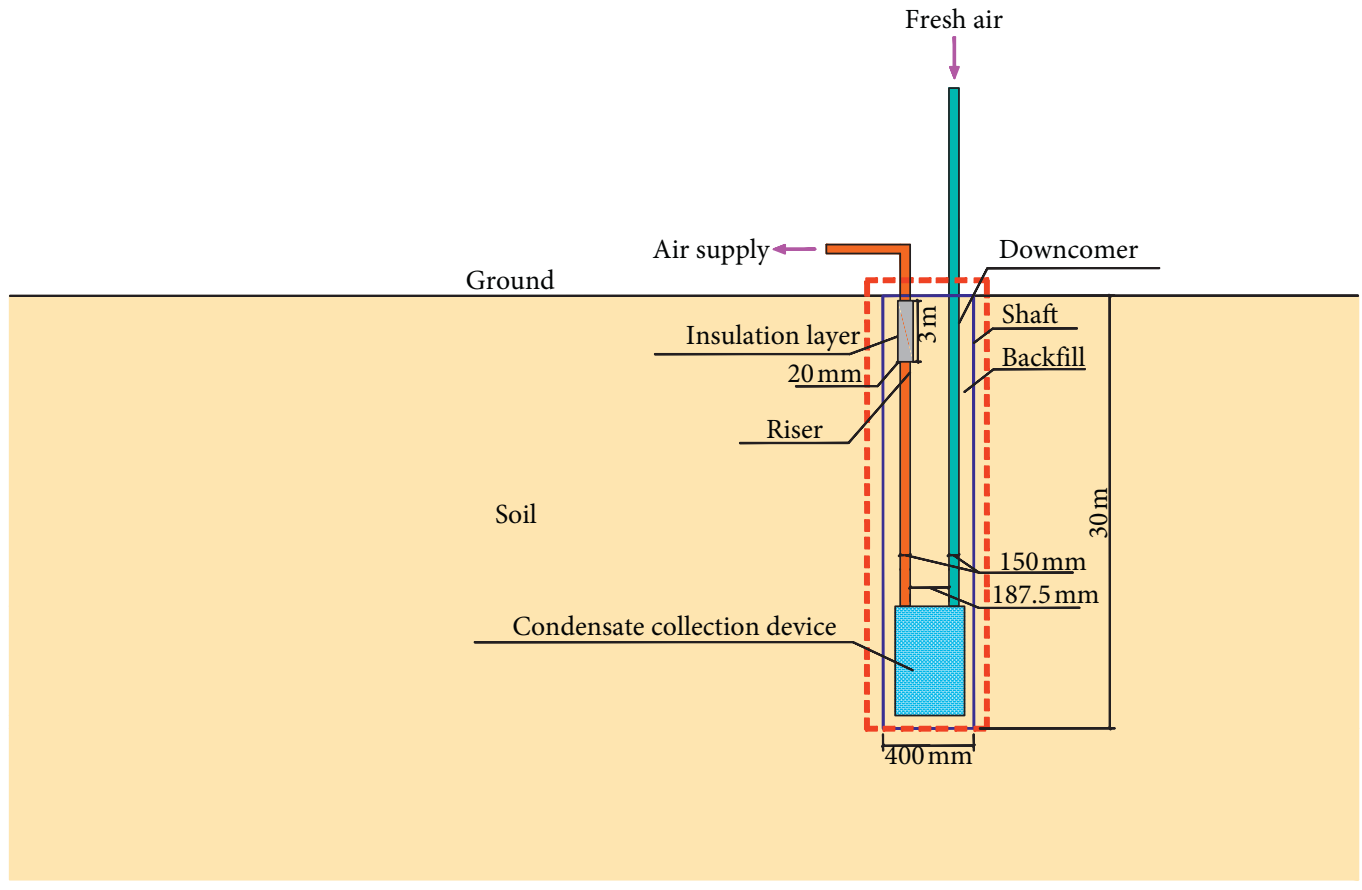

Figure 2: Schematic of the VEAHE system.

Compared with the traditional EAHE system, the advantage of the VEAHE system is that its single shaft occupies a small area (generally less than $1 \mathrm{~m}^{2}$ ), which reduces construction costs, while increasing the flexibility of application in densely built areas on the ground; its heat transfer depth is large (generally more than $20 \mathrm{~m}$ ), significantly improving the deep geothermal energy utilization; it is more conducive to concentratedly discharging condensed water, and it basically eliminates the deterioration of air quality for condensed water staying on the inner wall of the air ducts. 


\section{The Establishment of the Model}

3.1. Physical Model. The red dotted portion in Figure 2 is taken as the research object of the VEAHE system, ignoring the influences of the condensate collection device on the heat transfer of the system, which means the condensate collection device only plays a role in connecting the downcomers with the risers. The physical model of the VEAHE system is shown in Figure 3 based on the DesignModeler on the ANSYS Workbench platform. It includes three parts: the U-shaped air duct system, the backfill of the vertical shaft, and the soil area outside it. The parameters involved in the physical model of the VEAHE system are shown in Table 1.

3.1.1. Meshing and Irrelevance Check. The physical model is divided by tetrahedral meshes, which are suitable for complex geometric models or large ranges, sizes, and length of a process. Compared with hexahedral meshes, tetrahedral meshes are more adaptable to physical models and are mostly used for free meshing. At the same time, hexahedral meshes will have a much larger aspect ratio than tetrahedral meshes. This aspect ratio may affect the overall skewness of the grid, thereby hindering the accuracy and convergence of numerical calculations. The physical model is meshed, which comprised of 2.93 million cells with minimum and maximum element size of $0.2 \mathrm{~m}$ and $3.1 \mathrm{~m}$, respectively, at a growth rate of 1.2, and the maximum skewness of mesh is 0.84 . Generally, the maximum skewness less than 0.94 is considered as acceptable mesh precision. The final division result is shown in Figure 4.

Taking the air temperature $30 \mathrm{~m}$ away from the entrance of the VEAHE system as the standard, the grid division of the physical model is investigated for irrelevance check, and the calculation results are shown in Figure 5. The number of grids is changed by the size of the grid. During the process of increasing the number of grids, after the number of grids reaches 3 million, the temperature change rate at the inspection point becomes slow, and finally, the number of grids of the model is about 3 million.

3.2. Mathematical Model. ANSYS Fluent was used in the study that used the finite volume method to convert the governing equations into numerically solvable algebraic equations. The numerical simulation uses the supercomputer center for calculation, and Slurm is chosen as the dispatch system. The node CPU is Intel Xeon E5-2697R v4, the frequency is $2.3 \mathrm{GHz}$, the number of cores per node is 32 , and the memory is $128 \mathrm{~GB}$. In the calculation process, the value represented by each curve is lower than $10^{-6}$, which can be regarded as the calculation convergence. Therefore, the $60 \mathrm{~s}$ time step is used in the early stage and the $3600 \mathrm{~s}$ time step later. The numerical simulation is based on the following assumptions:

(1) There is no influence of the vertical shaft wall on heat transfer of soil. Assume that the thermal conductivity of the shaft wall is consistent with that of soil.

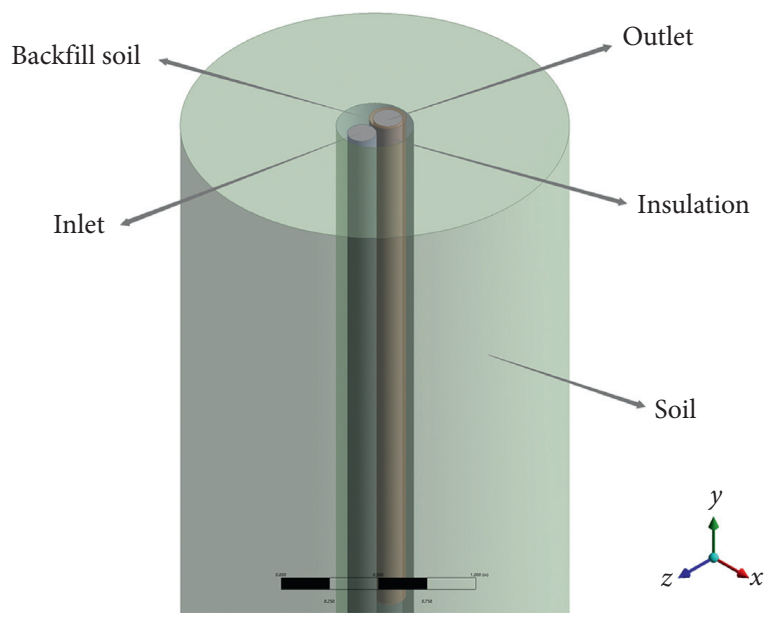

FIgUre 3: Physical geometry of the VEAHE system.

TABLe 1: The parameters involved in the VEAHE system.

\begin{tabular}{lcc}
\hline Parameters & Unit & Value \\
\hline Diameter of ducts & $\mathrm{mm}$ & 150 \\
Thickness of ducts & $\mathrm{mm}$ & 4 \\
Pitch distance & $\mathrm{mm}$ & 187.5 \\
Depth of buried ducts & $\mathrm{m}$ & 30 \\
Diameter of vertical shafts & $\mathrm{mm}$ & 400 \\
Diameter of soil field & $\mathrm{mm}$ & 2000 \\
Thickness of insulation layers & $\mathrm{mm}$ & 20 \\
Length of insulation layers & $\mathrm{m}$ & 3 \\
\hline
\end{tabular}

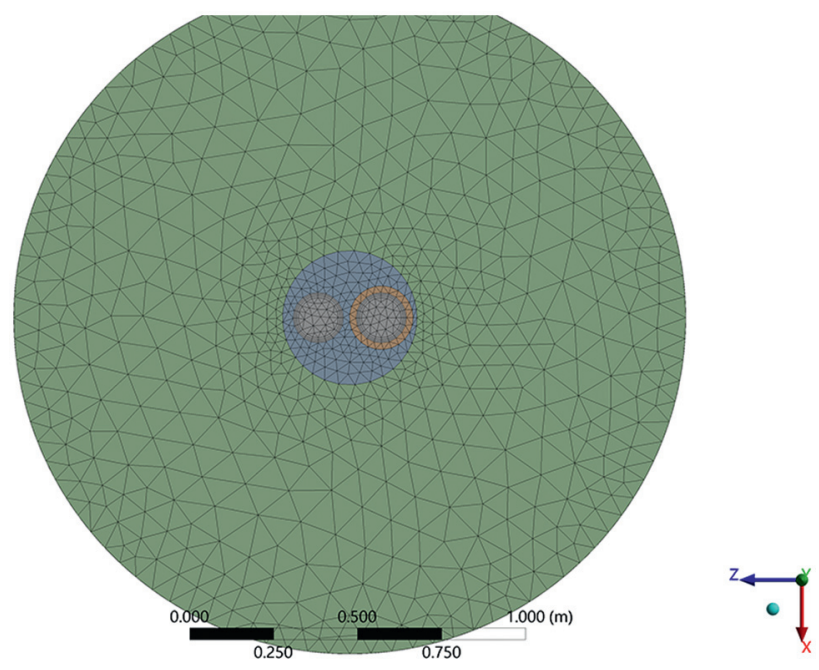

FIGURE 4: Meshing detail in the VEAHE system.

(2) During the heat transfer process, air is an incompressible fluid and the thermo-physical properties of soil and air remain constant.

(3) The air in ducts and the inner duct walls focus on convective heat transfer, while soil and the outer duct walls focus on heat conduction.

(4) There is no influence of air condensation on the inner duct walls. 


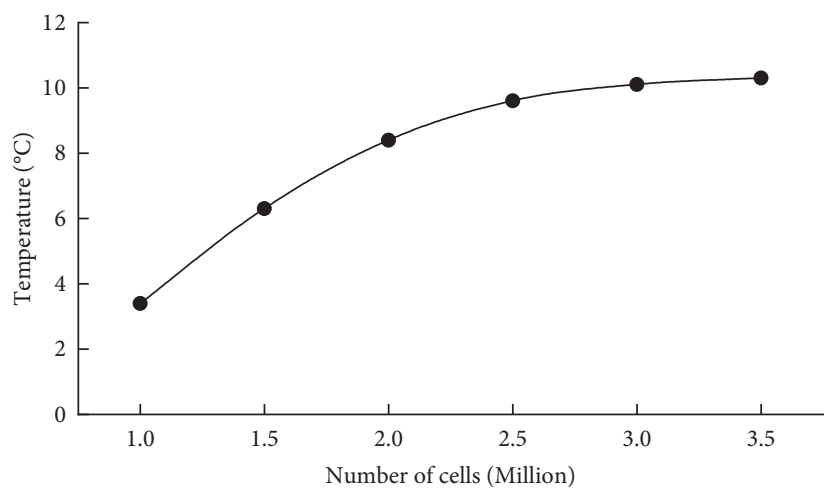

Figure 5: Mesh irrelevance check.

(5) Initially, the temperature of the air ducts and that of the soil layer are considered equal without regard to the contact thermal resistance between them.

(6) There is no influence of the water evaporation and migration in soil during summer and soil freezing during winter on heat transfer.

As for assumption 1, as mentioned above, the shaft mainly supports and protects the VEAHE system, and the effect of enhancing or weakening the heat transfer performance of the system is negligible. In other words, if the life requirements of the VEAHE system in actual process are not considered, the construction of the shaft can be cancelled. For assumption 4, air rarely condenses on the inner walls of the duct, but it basically only does under high humidity conditions in summer, which accounts for a small proportion in the entire operating cycle of the VEAHE system. At the same time, for the design in Figure 1, the condensate collection device could avoid this phenomenon. For assumption 6 , the evaporation and migration of water in the soil in summer and the freezing of the soil in winter mostly happen in shallow areas, greatly affected by environmental temperature. These conditions will hardly cause the average soil thermal conductivity to decrease. Changes have negligible impacts on the heat transfer between the VEAHE system and the soil.

3.2.1. Governing Equations. The governing equations of heat and mass transfer of the fluid flow consist of the continuity equation, the momentum equation, the energy equation, and the realizable $k-\varepsilon$ equation.

The continuity equation is as follows:

$$
\frac{\partial \rho}{\partial t}+\nabla \cdot(\rho \vec{v})=S_{m}
$$

where $\rho\left(\mathrm{kg} \mathrm{m}^{-3}\right)$ is the density of the fluid, $t(\mathrm{~s})$ is the time, $\vec{v}(\mathrm{~m} / \mathrm{s})$ is the velocity vector of the flow, and $S_{m}\left(\mathrm{~kg} \mathrm{~m}^{-3} \mathrm{~s}^{-1}\right)$ is the source term of mass.

The momentum equation is as follows:

$$
\frac{\partial}{\partial t}(\rho \vec{v})+\nabla \cdot(\rho \vec{v} \vec{v})=-\nabla p+\nabla \cdot(\overline{\bar{\tau}})+\rho \vec{g}+\vec{F}
$$

where $\rho\left(\mathrm{kg} \mathrm{m}^{-3}\right)$ is the density of the fluid, $p\left(\mathrm{~N} \mathrm{~m}^{-2}\right)$ is the fluid static pressure, $t(\mathrm{~s})$ is the time, $\rho \vec{g}\left(\mathrm{~N} \mathrm{~m}^{-3}\right)$ is the gravitational body force per unit volume, $\vec{F}\left(\mathrm{~N} \mathrm{~m}^{-3}\right)$ is other energy items caused by resistance and energy, $\vec{v}(\mathrm{~m} / \mathrm{s})$ is the velocity vector of the flow, and $\overline{\bar{\tau}}\left(\mathrm{N} \mathrm{m}^{-2}\right)$ is the viscous stress tensor related to surface forces on an infinitesimal element of fluid, which is defined by

$$
\overline{\bar{\tau}}=\mu\left(\nabla \vec{v}+\nabla \vec{v}^{T}\right)-\frac{2}{3} \nabla \vec{v} I,
$$

where $\mu\left(\mathrm{kg} \mathrm{m}^{-1} \mathrm{~s}^{-1}\right)$ is the molecular viscosity, $\vec{v}(\mathrm{~m} / \mathrm{s})$ is the velocity vector of the flow, and $I$ is an unitary tensor.

The energy equation is as follows:

$$
\frac{\partial}{\partial t}(\rho E)+\nabla \cdot(\vec{v}(\rho E+p))=\nabla \cdot\left(k_{\mathrm{eff}} \nabla T-\sum h_{j} \overrightarrow{J_{J}}+\left(\overline{\overline{\tau_{\mathrm{eff}}}} \cdot \vec{v}\right)\right)+S_{h}
$$

where $\rho\left(\mathrm{kg} \mathrm{m}^{-3}\right)$ is the density of the fluid, $t$ (s) is the time, $\vec{v}(\mathrm{~m} / \mathrm{s})$ is the velocity vector of the flow, $p\left(\mathrm{~N} \mathrm{~m}^{-2}\right)$ is the fluid static pressure, $T\left({ }^{\circ} \mathrm{C}\right)$ is the temperature, and $E\left(\mathrm{~J} \mathrm{~kg}^{-1}\right), h_{j}\left(\mathrm{~J} \mathrm{~kg}^{-1}\right)$, and $k_{\text {eff }}\left(\mathrm{W} \mathrm{m}^{-1} \mathrm{~K}^{-1}\right)$ are the total energy of the infinitesimal element of fluid (including the internal energy, kinetic energy, and potential energy of fluid), the enthalpy of species $j$, and the effective conductivity, respectively. The calculations are as follows:

$$
\begin{aligned}
E & =h-\frac{p}{\rho}+\frac{v^{2}}{2}, \\
h & =\sum_{j} Y_{j} h_{j}+\frac{p}{\rho}, \\
h_{j} & =\int_{T_{\text {ref }}}^{T} C_{p j} \mathrm{~d} T, \\
k_{\mathrm{eff}} & =k+k_{t},
\end{aligned}
$$


where $\rho\left(\mathrm{kg} \mathrm{m}^{-3}\right)$ is the density of the fluid, $v(\mathrm{~m} / \mathrm{s})$ is the velocity, $p\left(\mathrm{~N} \mathrm{~m}^{-2}\right)$ is the fluid static pressure, $h\left(\mathrm{~J} \mathrm{~kg}^{-1}\right)$ is the sensible enthalpy, $Y_{j}$ is the mass fraction of species $j, C_{p j}$ $\left(\mathrm{J} \mathrm{kg}^{-1} \mathrm{~K}^{-1}\right)$ is the specific heat of species $j, T_{\text {ref }}$ is the lower limit of temperature $\left(T_{\text {ref }}=298.15 \mathrm{~K}\right), k_{t}\left(\mathrm{~W} \mathrm{~m}^{-1} \mathrm{~K}^{-1}\right)$ is the turbulent thermal conductivity defined according to the turbulence model adopted, based on the turbulence model selected by the user, $\overrightarrow{J_{J}}\left(\mathrm{~kg} \mathrm{~m}^{-3} \mathrm{~s}^{-1}\right)$ is the diffusion flux of species $j$, and $S_{h}\left(\mathrm{~W} \mathrm{~m}^{-3}\right)$ is the source term of energy.

Given that turbulence is at the flow state, it is complicated to solve the governing equations. Turbulence flows unsteadily and irregularly. These properties reflected in the transportation volume, such as mass fraction, momentum, and species scalar, will fluctuate with time and space. The fluctuation causes the pulsation of the transportation volume, and the turbulent motion enhances the flow combination. The motion is irregular and random, but its statistical average is regular and could be described by an equation. Consequently, it is feasible to choose the pressure-based realizable $k-\varepsilon$ model, the submodel of RANS, with enhanced wall treatment and energy equation. The added expressions and transmission equations are as follows:

$$
\begin{aligned}
& \frac{\partial}{\partial t}(\rho k)+\frac{\partial}{\partial x_{j}}\left(\rho k u_{j}\right)=\frac{\partial}{\partial x_{j}}\left(\mu+\frac{\mu_{I}}{\sigma_{k}}\right) \frac{\partial k}{\partial x_{j}}+G_{k}+G_{b}-\rho \varepsilon-Y_{m}+S_{k}, \\
& \frac{\partial}{\partial t}(\rho \varepsilon)+\frac{\partial}{\partial x_{j}}\left(\rho \varepsilon u_{j}\right)=\frac{\partial}{\partial x_{j}}\left(\mu+\frac{\mu_{I}}{\sigma_{\varepsilon}}\right) \frac{\partial \varepsilon}{\partial x_{j}}+\rho C_{1} S_{\varepsilon}-\rho C_{2} \frac{\varepsilon^{2}}{k+\sqrt{\nu \varepsilon}}+C_{1 \varepsilon} \frac{\varepsilon}{k} C_{3 \varepsilon} G_{b}+S_{\varepsilon},
\end{aligned}
$$

where $\rho\left(\mathrm{kg} \mathrm{m}^{-3}\right)$ is the density of the fluid, $t(\mathrm{~s})$ is the time, $\mu$ $\left(\mathrm{kg} \mathrm{m}^{-1} \mathrm{~s}^{-1}\right)$ is the molecular viscosity, $k\left(\mathrm{~m}^{2} \mathrm{~s}^{-2}\right)$ is the turbulent kinetic energy, $\varepsilon\left(\mathrm{m}^{2} \mathrm{~s}^{-3}\right)$ is the turbulent dissipation rate, $G_{k}$ is the generation of turbulence kinetic energy affected by the mean velocity gradients, $G_{b}$ is the generation of turbulence kinetic energy affected by buoyancy, $S_{k}$ and $S_{\varepsilon}$ are user-defined source terms, $Y_{m}$ reveals the contribution of the fluctuating dilatation in compressible turbulence to the overall dissipation rate, $C_{2}$ and $C_{1 \varepsilon}$ are constants, generally, 1.4 and 1.9, respectively, and $\sigma_{k}$ and $\sigma_{\varepsilon}$ are the turbulent Prandtl numbers of turbulent kinetic energy and turbulent dissipation rate, respectively. The constants in the equations are defined as follows:

$$
\begin{aligned}
C_{1} & =\left[\max 0.43, \frac{\eta}{\eta+5}\right], \\
\eta & =S \frac{k}{\varepsilon}, \\
S & =\sqrt{2 S_{i j} S_{i j}} .
\end{aligned}
$$

\subsubsection{The Calculation of the Original Soil Temperature.} The temperature field of the soil of the inner stratum is a function of time and space with the combined effects of its thermal balance and thermal properties, and the function can be written as $\theta=f(y, \tau)$. In the analysis of the undisturbed original soil temperature, the stratum is considered as a kind of semi-infinite solid and Fourier's law is applied to calculate the heat conduction. For the homogeneous and semi-infinite soil temperature field with periodic boundary conditions, it can be described by a one-dimensional thermal conductivity differential equation as follows:

$$
\frac{\partial \theta}{\partial \tau}=a \frac{\partial^{2} \theta}{\partial y^{2}}
$$

where $\theta\left({ }^{\circ} \mathrm{C}\right)$ is the excess temperature, $\tau(\mathrm{s})$ is the time, $y(\mathrm{~m})$ is the soil depth, and $a\left(\mathrm{~m}^{2} / \mathrm{h}\right)$ is the soil thermal diffusion rate.

After the above formula is integrated and solved, the temperature field of the ground surface (semi-infinite object) under periodic action can be obtained. The expression is as follows:

$$
\theta=A_{d} e^{-y \sqrt{\pi / Z}} \cos \left(\frac{2 \pi}{Z} \tau-y \sqrt{\frac{\pi}{a Z}}\right),
$$

where $Z(\mathrm{~h})$ is the period of the temperature wave, $y(\mathrm{~m})$ is the soil depth, $A_{d}\left({ }^{\circ} \mathrm{C}\right)$ is the amplitude of temperature of the ground surface, $\tau(\mathrm{s})$ is the time, and $a\left(\mathrm{~m}^{2} / \mathrm{h}\right)$ is the thermal diffusivity of the ground surface material.

If we are taking $\Omega=2 \pi / Z$ as the fluctuation frequency, the following equation can be obtained:

$$
\theta=A_{d} e^{-y \sqrt{\Omega / 2 a}} \cos \left(\Omega \tau-y \sqrt{\frac{\Omega}{2 a}}\right) .
$$

Since $\theta\left({ }^{\circ} \mathrm{C}\right)$ is the value of excess temperature at a certain moment at a certain depth of the ground surface, there is the following expression:

$$
\theta=t(y, \tau)-t_{d}
$$

Consequently, the soil temperature at any depth and at any time can be described as

$$
T=t_{d}+A_{d} e^{-y \sqrt{\Omega / 2 a}} \cos \left(\Omega \tau-y \sqrt{\frac{\Omega}{2 a}}\right),
$$

where $A_{d}\left({ }^{\circ} \mathrm{C}\right)$ is the amplitude of temperature of the ground surface, $t_{d}\left({ }^{\circ} \mathrm{C}\right)$ is the annual average temperature of the ground surface, and $a\left(\mathrm{~m}^{2} / \mathrm{h}\right)$ is the thermal diffusivity of the ground surface material. 
3.2.3. Initial and Boundary Conditions. The initial condition of the VEAHE system can be regarded as the temperature distribution of its physical model at the beginning of the numerical simulation. The air temperature in the ducts is considered the same as that of the surrounding soil at the same depth. The boundary conditions of the VEAHE system mainly include the following situations:

(1) The temperature at the inlet of the system is the same as the temperature at the inlet of the outdoor air. As the solar radiation changes periodically every day, the air temperature reveals a fluctuation trend. Therefore, it is necessary to conduct curve fitting on the temperature data of outdoor air hourly, compile the temperature functional expression obtained in the form of the predefined macrofunction DEFINE_PROFILE, and load it into the user in the userdefined function (UDF), named $U F_{i n}$, to define the boundary conditions of the inlet temperature of the air ducts.

(2) As mentioned above, the soil surface is affected by many factors, so it can be simplified to a single wall thermal boundary condition only affected by the outdoor air temperature and defined by $\mathrm{UDF}_{\text {in }}$.

(3) The boundaries of the outlet of the system are the same as those of air. The air in the air ducts is considered as an incompressible fluid, the air pressure at the outlet is unknown, and the air motion is in the fully developed stage, so the boundary condition of the outlet is a free outflow term.

(4) Taking into account the vertical distribution of soil temperature, compile equation (12) in the form of the predefined macrofunction DEFINE_INIT and load it into UDF. In the equation, the values of $A_{d}, t_{d}$, $a$, and $c$ are, respectively, taken from the research conducted in local areas. This function, $\mathrm{UDF}_{\text {soil, }}$, is used to initialize the undisturbed original temperature field of soil, which acts on the whole soil field without any return value. In such a way, the boundary condition of soil temperature is defined.

\section{Model Verification}

In order to verify the correctness and reliability of the mathematical model, Liu et al. [33] built an experimental platform of the VEAHE system in Changsha, Hunan Province, as shown in Figure 6, where the air duct diameter was $219 \mathrm{~mm}$, the air duct depth $15.5 \mathrm{~m}$, the pitch distance $681 \mathrm{~mm}$, and the shaft diameter $1 \mathrm{~m}$. In order to specifically explore the actual thermal performance of the VEAHE system, the experiment was carried out from August 20th to August 24th in summer and from December 30th to January 3rd of the following year (subtropical monsoon climate [34]). The outlet air temperature was detected and recorded in the case of constant air volume $(0.047 \mathrm{~kg} / \mathrm{s})$.

In summer, the outdoor air temperature fluctuated between 27.0 and $39.0^{\circ} \mathrm{C}$. The overall average temperature hit $32.3^{\circ} \mathrm{C}$, and the average temperature of the air outlet after heat exchange by the VEAHE system registered $23.5^{\circ} \mathrm{C}$. In addition, the single-day average temperature difference of outdoor air was $10.6^{\circ} \mathrm{C}$, which decreased to $1.3^{\circ} \mathrm{C}$ after the system was applied, as shown in Figure 7(a). Under winter conditions, the outdoor air temperature fluctuated between 3.0 and $15.0^{\circ} \mathrm{C}$, and the overall average temperature registered $7.3^{\circ} \mathrm{C}$. After the heat exchange of the VEAHE system, the average temperature of the air outlet rose to $16.7^{\circ} \mathrm{C}$. In addition, the average daily temperature difference of outdoor air was $6.8^{\circ} \mathrm{C}$, and after the system was applied, it dropped to $1.0^{\circ} \mathrm{C}$, as shown in Figure $7(\mathrm{~b})$. The above data showed that the VEAHE system has a significant cooling or warming effect on outdoor high or low temperature.

$\mathrm{UDF}_{\text {in }}$ and $\mathrm{UDF}_{\text {soil }}$ were loaded to calculate the temperature of the inlet of the VEAHE system and its original soil temperature, respectively. Then, simulation calculation was conducted for 96 consecutive hours on the system. The simulation results showed that the average temperatures of the air outlet of the system during summer and winter registered $21.6^{\circ} \mathrm{C}$ and $15.5^{\circ} \mathrm{C}$, respectively. The errors of maximum absolute values of the system in summer and winter were $1.9^{\circ} \mathrm{C}$ and $1.2^{\circ} \mathrm{C}$, and the relative errors of the maximum absolute values were $8.1 \%$ and $7.2 \%$, respectively. Figure 7 shows the comparison between the results of numerical simulation and experimental data. Figure 8 shows the temperature distribution of the surrounding soil after heat transfer of the system. Therefore, it could come into a conclusion that the VEAHE system numerical model is correct, and it could be used to predict and analyze the thermal performance of the system in future research.

\section{Analysis of Factors Influencing the Thermal Performance of the VEAHE System}

In the research, Beijing, a typical city in cold regions, was selected as an example. According to the meteorological parameters of Beijing, the hourly temperatures of the local winter and summer within seven days were selected for curve fitting. The fitting results are shown in Figure 9. The basic physical parameter values involved in the VEAHE system are shown in Table 2.

Usually, for the engineering design calculation, only the operation conditions of the coldest month (or the hottest month) need to be calculated. Therefore, for the research in this article, the equation of the operation condition in the coldest month can be simplified as follows:

$$
T=t_{d}-A_{d} e^{-y \sqrt{\Omega / 2 a}} \cos \left(-y \sqrt{\frac{\Omega}{2 a}}\right),
$$

where $t_{d}=13.1^{\circ} \mathrm{C}, A_{d}=15.4^{\circ} \mathrm{C}$, and $a=0.00318 \mathrm{~m}^{2} / \mathrm{h}$, and at this time, $\sqrt{\Omega / 2 a}=0.334$. So, the equation above can be simplified as

$$
T=13.1-15.4 e^{-0.334 y} \cos (0.334 y) .
$$

The equation of the operation condition in the hottest month can be simplified as 

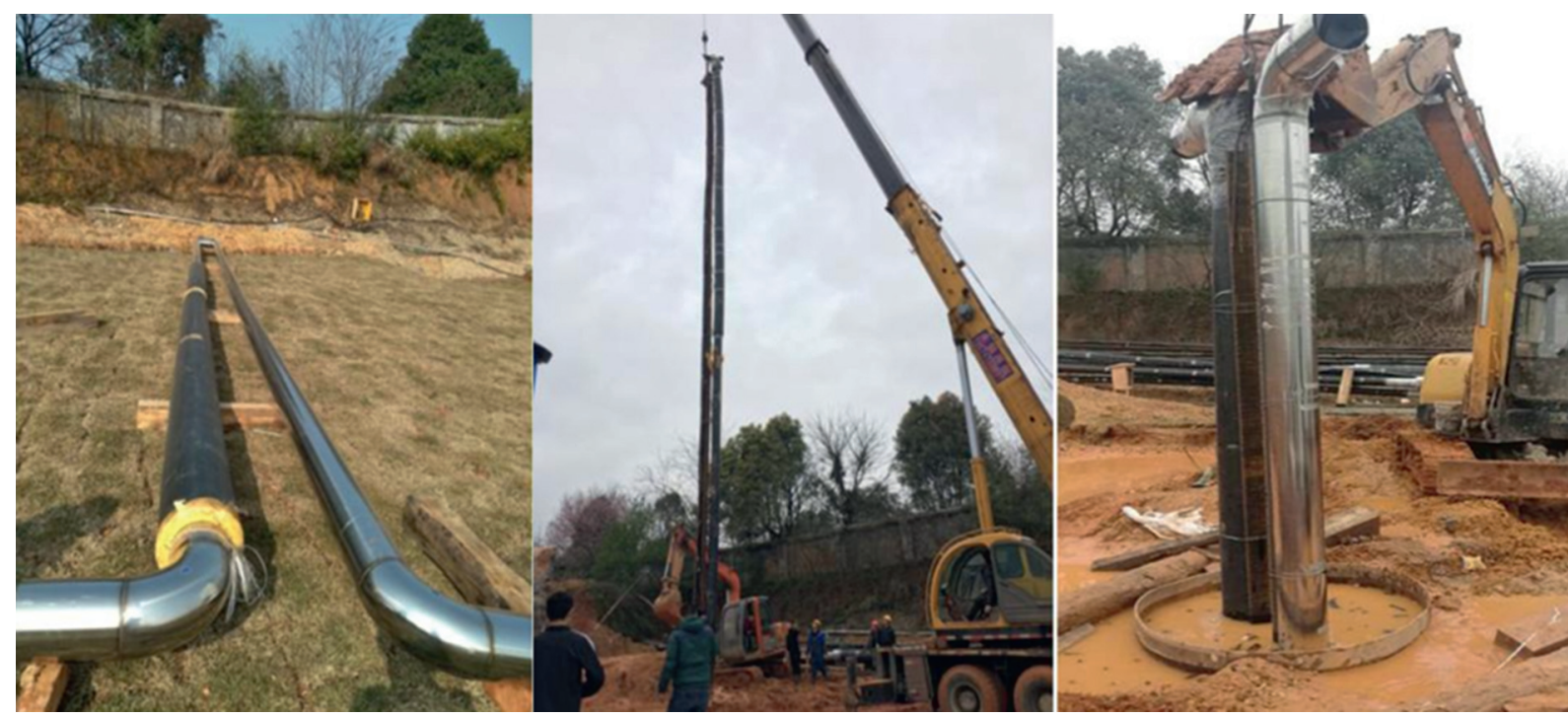

Figure 6: Schematic of the VEAHE system.

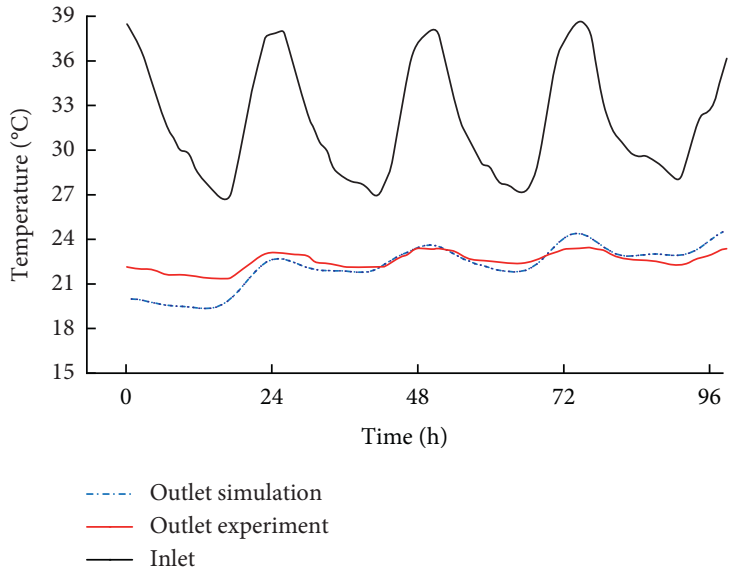

(a)

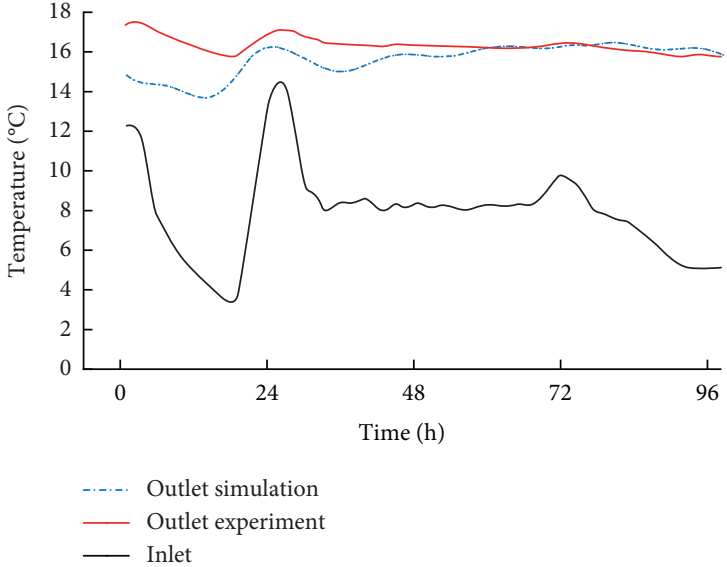

(b)

Figure 7: (a) Comparison of experimental data and simulation results under summer condition. (b) Comparison of experimental data and simulation results under winter condition.

$$
T=13.1+15.4 e^{-0.334 y} \cos (0.334 y)
$$

\subsection{Influences of Parameters of Ducts}

5.1.1. Influences of Duct Materials. With other parameters unchanged, four different duct materials including ductile iron, stainless steel, PE, and PVC exert the influences shown in Figure 10 on the temperature at the outlet of the system in winter and summer. The thermal conductivities of the four types of ducts are $45\left(\mathrm{~W} \mathrm{~m}^{-1} \mathrm{~K}^{-1}\right), 16.2\left(\mathrm{~W} \mathrm{~m}^{-1} \mathrm{~K}^{-1}\right), 0.42$ $\left(\mathrm{W} \mathrm{m}^{-1} \mathrm{~K}^{-1}\right)$, and $0.14\left(\mathrm{~W} \mathrm{~m}^{-1} \mathrm{~K}^{-1}\right)$, respectively.

For the operation conditions in winter, the average temperatures of the air outlet of the systems of the 4 types are $9.5^{\circ} \mathrm{C}, 9.5^{\circ} \mathrm{C}, 9.3^{\circ} \mathrm{C}$, and $9.1^{\circ} \mathrm{C}$, respectively. The air temperature at the outlet of the system increases as the thermal conductivity of ducts rises, and with the increase of the latter, the increase rate of the former tends to be reduced. Consequently, it is of little significance to use ducts of high thermal conductivity to enhance the heat transfer performance. In Figure 10(a), different materials of air ducts have an impact which, however, is subtle, on the air temperature of the outlet. In Figure 10(a), the lower the air temperature of inlet hits, the more sharply the temperature rises through the VEAHE system and the more efficient the heat transfer will be. The VEAHE system plays an effective role in stabilizing and suppressing the air temperature fluctuation of the inlet, and this effect becomes better as time passes. In engineering applications, due to the high cost of metal ducts with strict construction requests, PE or PVC could be plausible choices for the materials of air ducts, which is the same as the conclusions given in paper $[2,35]$.

The operation conditions in summer are shown in Figure 10(b), and the discussion will not be repeated here. 


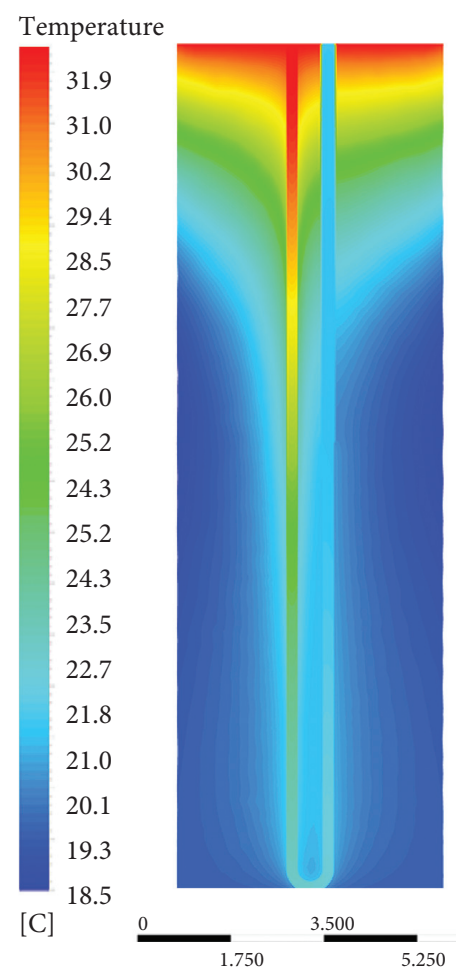

(a)

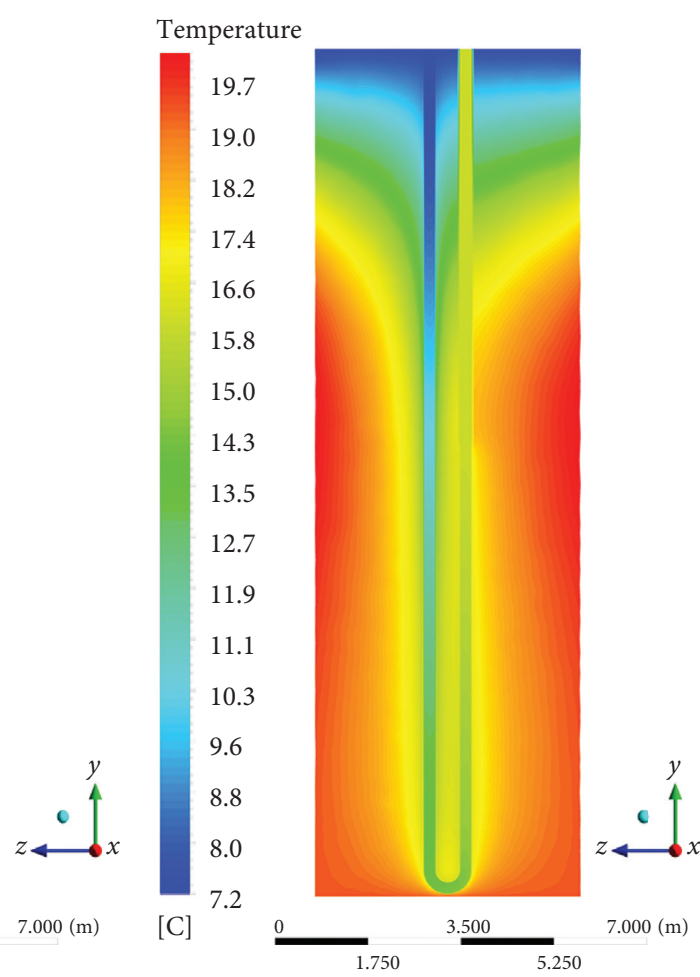

(b)

Figure 8: (a) The temperature distribution of the soil after the heat transfer under summer condition. (b) The temperature distribution of the soil after the heat transfer under winter condition.

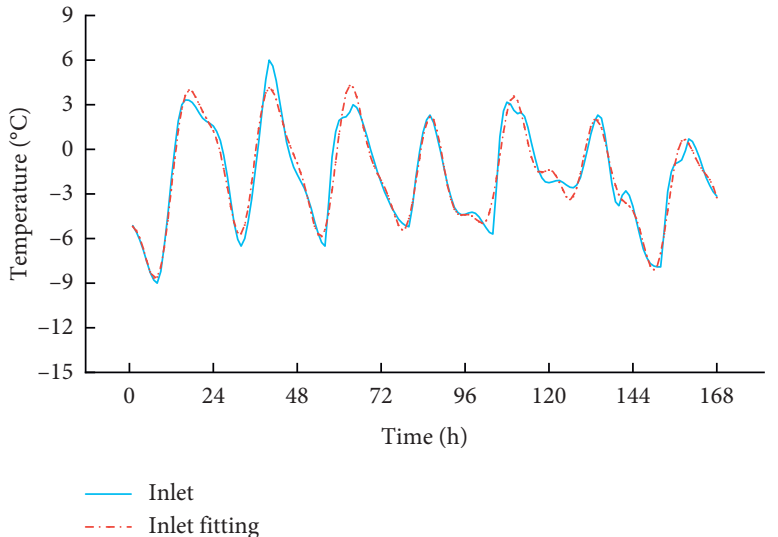

(a)

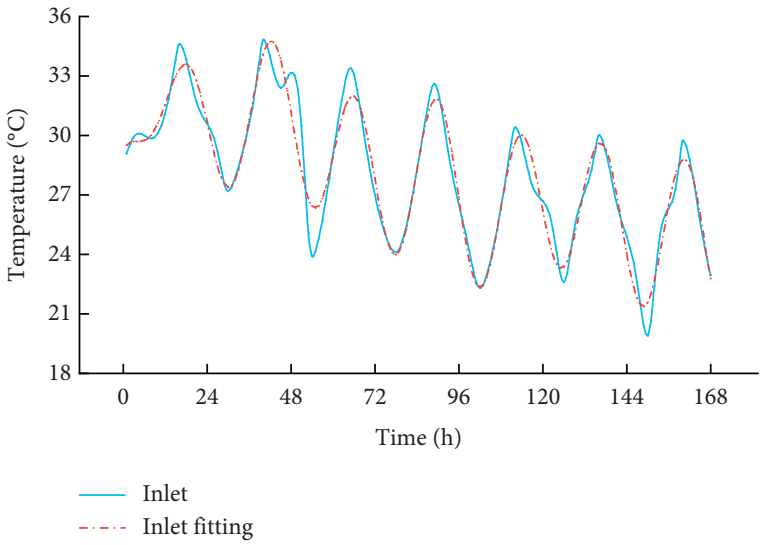

(b)

Figure 9: (a) Comparison of winter air temperature and fitting temperature. (b) Comparison of summer air temperature and fitting temperature.

TABLe 2: Basic physical parameter value.

\begin{tabular}{lcc}
\hline Parameters & Unit & Value \\
\hline Duct material & $\mathrm{W} \mathrm{m}^{-1} \mathrm{~K}^{-1}$ & 0.42 \\
Insulation material & $\mathrm{W} \mathrm{m}^{-1} \mathrm{~K}^{-1}$ & 0.024 \\
Soil thermal conductivity & $\mathrm{W} \mathrm{m}^{-1} \mathrm{~K}^{-1}$ & 1.46 \\
Soil temperature diffusivity & $\mathrm{m}^{2} / \mathrm{h}$ & 0.00318 \\
Soil specific heat capacity & $\mathrm{J} \mathrm{kg} \mathrm{K}^{-1}$ & 1260 \\
Soil density & $\mathrm{kg} \mathrm{m}^{-3}$ & 1312 \\
Air velocity & $\mathrm{m} / \mathrm{s}$ & 3 \\
\hline
\end{tabular}




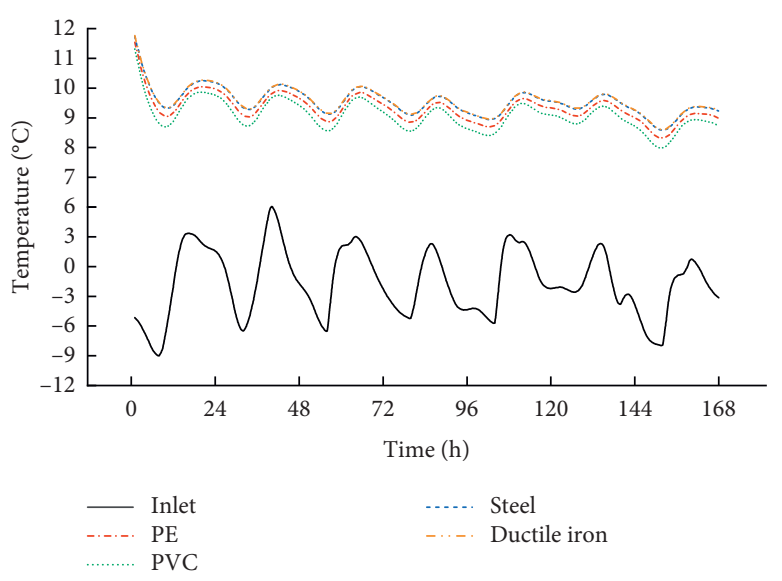

(a)

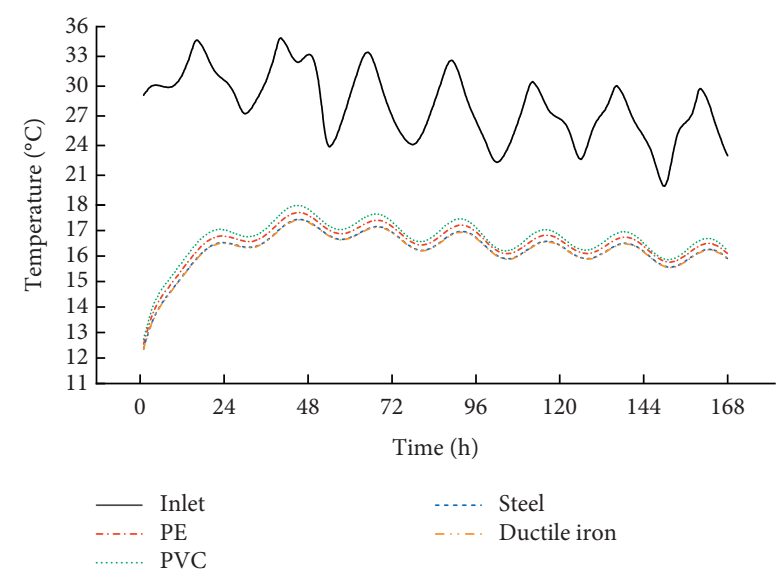

(b)

Figure 10: (a) The influence of duct materials on the outlet air temperature in winter. (b) The influence of duct materials on the outlet air temperature in summer.

5.1.2. Influences of Pitch Distance. With other parameters unchanged and the risers without insulation layers, 6 different pitch distances including 1.1 D, 1.2 D, 1.3 D, 1.4 D, 1.5 $\mathrm{D}$, and $1.6 \mathrm{D}$ (where $\mathrm{D}$ represents the diameter of the ducts) exert influences shown in Figure 11 on the air temperature at the outlet of the system during winter and summer.

For the operation conditions in winter, with the pitch distances varying from $1.1 \mathrm{D}$ to $1.6 \mathrm{D}$, the average temperatures of the air outlet of the system are $8.4^{\circ} \mathrm{C}$, $8.6^{\circ} \mathrm{C}, 8.7^{\circ} \mathrm{C}, 8.9^{\circ} \mathrm{C}, 9.0^{\circ} \mathrm{C}$, and $9.1^{\circ} \mathrm{C}$, and the air temperature of the air outlet increases as the pitch distance increases. This is because when the pitch distance is small, the air of low temperature at the inlet of the downcomer will have a cooling effect to some extent on the hot air at the outlet of the riser, thereby affecting the air temperature at the outlet. As the pitch distance gradually increases, this impact will be gradually reduced. In Figure 11(a), different pitch distances have an effect which, however, is subtle, on the air temperature of the outlet. Due to the increase of pitch distance, the cost of drilling rises. It is not advisable to increase the pitch distance. In practical engineering applications, insulation layers can be laid on risers at a depth of $3 \mathrm{~m}$ to reduce the influences of downcomers on risers. (the details are elaborated at 5.3 for the influence of the insulation layer on the heat transfer performance of the system). Meanwhile, taking into account the convenience of laying insulation layers, the pitch distance at $1.2-1.3 \mathrm{D}$ is advisable in practical engineering applications.

The operation conditions in summer are shown in Figure 11(b), and the discussion will not be repeated here.

5.1.3. Influences of Diameters of Ducts. With other parameters unchanged and the risers without insulation layers, 7 different diameters of ducts including $100 \mathrm{~mm}, 120 \mathrm{~mm}$, $150 \mathrm{~mm}, 180 \mathrm{~mm}, 200 \mathrm{~mm}, 250 \mathrm{~mm}$, and $300 \mathrm{~mm}$ exert the influences shown in Figure 12 on the air temperature at the outlet of the system during winter and summer.
For the operation conditions in winter, the average temperatures of the outlet of the systems with ducts of 7 different diameters are $11.0^{\circ} \mathrm{C}, 10.5^{\circ} \mathrm{C}, 9.3^{\circ} \mathrm{C}, 8.1^{\circ} \mathrm{C}, 7.4^{\circ} \mathrm{C}$, $5.6^{\circ} \mathrm{C}$, and $4.5^{\circ} \mathrm{C}$, respectively. The air temperature at the outlet of the system decreases as the diameter of ducts rises. In Figure 12(a), different duct diameters exert a significant effect on the air temperature at the outlet. The shorter the duct diameter is, the more sharply the temperature will rise and the more steadily the air temperature at the outlet fluctuates. With the diameter at $250 \mathrm{~mm}$, the fluctuation amplitude of the air temperature at the outlet obviously increases. Although a smaller diameter of the duct supplies more heat to the system, it could hardly meet the demand of indoor fresh air. At the same time, a larger diameter of the duct will lower the temperature at the outlet and bring huge initial investment for the system. Consequently, with regard to the overall economy of the system, it is advisable to choose the diameter of the duct at $150-250 \mathrm{~mm}$ in practical engineering applications.

The operation conditions in summer are shown in Figure 12(b), and the discussion will not be repeated here.

5.1.4. Influences of Buried Depth of Ducts. With other parameters unchanged, 7 different buried depths of ducts including $0 \mathrm{~m}, 25 \mathrm{~m}, 30 \mathrm{~m}, 35 \mathrm{~m}, 40 \mathrm{~m}, 45 \mathrm{~m}$, and $50 \mathrm{~m}$ exert the influences shown in Figure 13 on the air temperature at the outlet of the system during winter and summer.

For the operation conditions in winter, the average temperatures of the outlet of the systems with ducts buried at 7 depths are $7.5^{\circ} \mathrm{C}, 8.6^{\circ} \mathrm{C}, 9.3^{\circ} \mathrm{C}, 9.8^{\circ} \mathrm{C}, 10.1^{\circ} \mathrm{C}, 10.3^{\circ} \mathrm{C}$, and $10.5^{\circ} \mathrm{C}$, respectively. The air temperature at the outlet of the system increases as the buried depth of ducts rises. In Figure 13(a), the diversity of buried depths of ducts exerts a significant effect on the air temperature at the outlet. The more deeply the ducts are laid, the more sharply the temperature will rise and the more steadily the air temperature at the outlet fluctuates as the temperature at the 


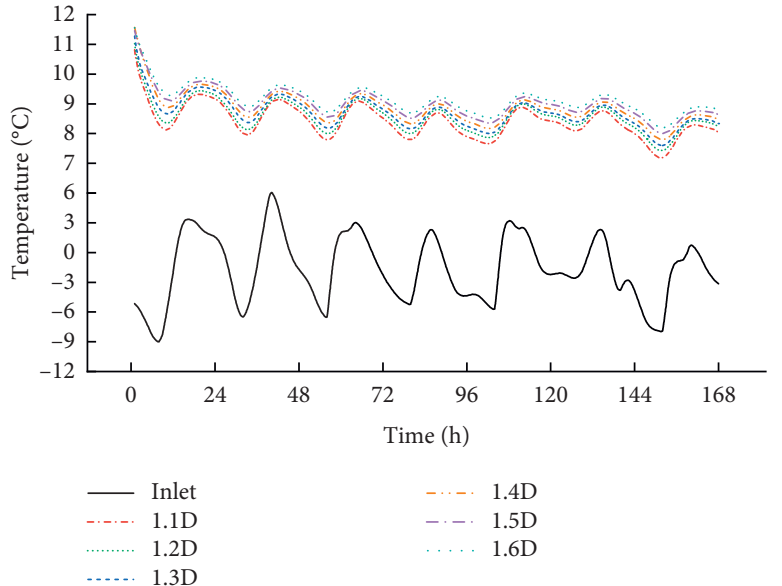

(a)

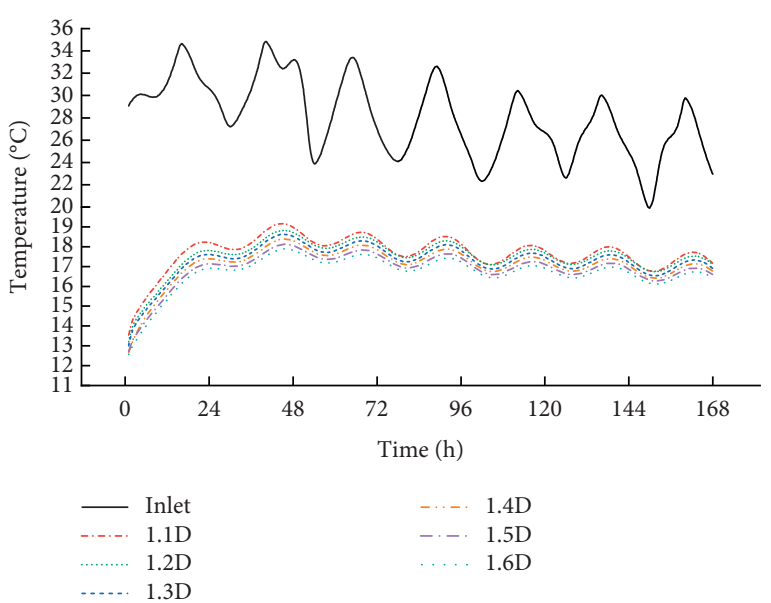

(b)

Figure 11: (a) The influence of pitch distances on the outlet air temperature in winter. (b) The influence of pitch distances on the outlet air temperature in summer.

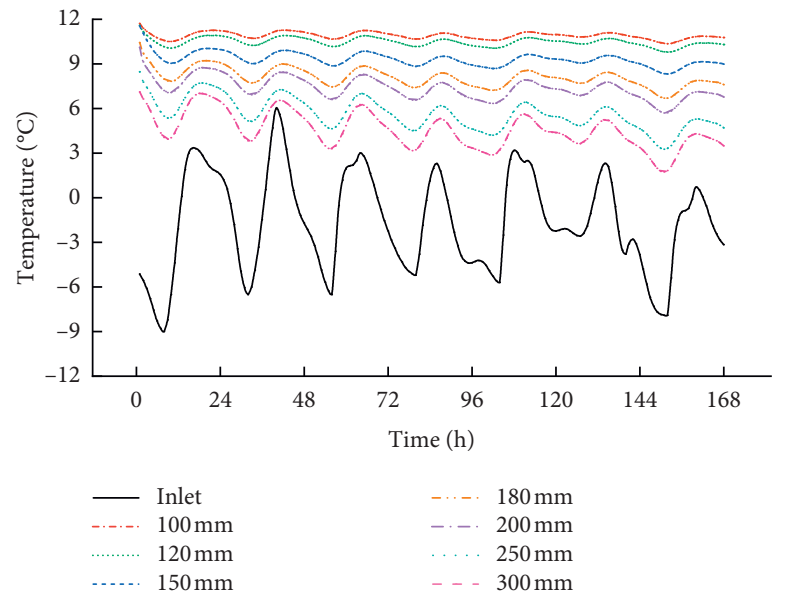

(a)

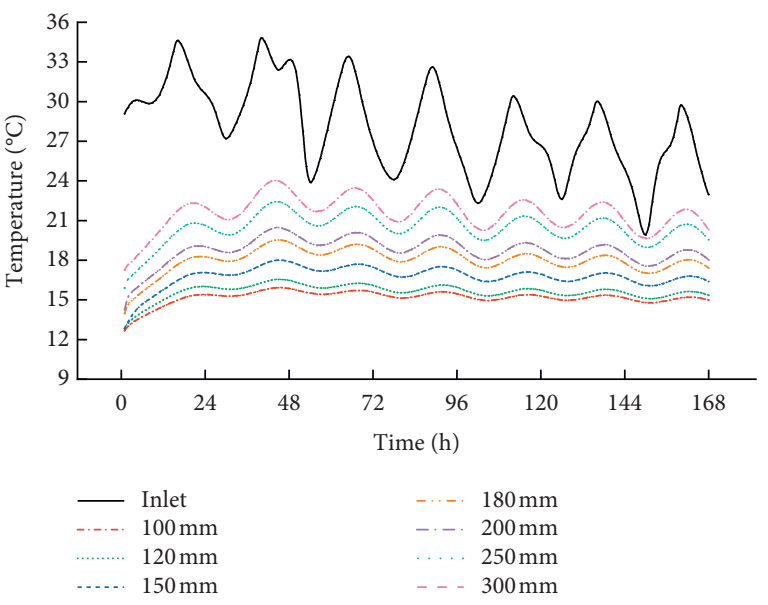

(b)

Figure 12: (a) The influence of diameters of ducts on the outlet air temperature in winter. (b) The influence of diameters of ducts on the outlet air temperature in summer.

inlet changes. With the rise of depth of buried ducts and larger area of heat transfer, the heat exchange is enhanced. Given that the soil temperature at the outlet increases less sharply than the depth of ducts does, the air temperature increases less and less sharply with the rise of depth of ducts (as the depth of buried ducts increases from $20 \mathrm{~m}$ to $30 \mathrm{~m}$, the average temperature at the outlet rises by $1.6^{\circ} \mathrm{C}$. As the depth increases from $40 \mathrm{~m}$ to $50 \mathrm{~m}$, the average temperature increases by $0.4^{\circ} \mathrm{C}$ correspondingly). The increase in the depth of buried ducts will bring more cost for drilling and ducts. It is not an effective way to simply increase the depth for higher temperature at the outlet. Therefore, it is advisable to choose the depth at $30-40 \mathrm{~m}$ in cold regions or $40-50 \mathrm{~m}$ in severe cold areas, in practical engineering applications.

The operation conditions in summer are shown in Figure 13(b), and the discussion will not be repeated here.
5.2. Influences of Air Velocity in Ducts. With other parameters unchanged, 7 different air velocities in ducts including $3 \mathrm{~m} / \mathrm{s}, 4 \mathrm{~m} / \mathrm{s}, 5 \mathrm{~m} / \mathrm{s}, 6 \mathrm{~m} / \mathrm{s}, 7 \mathrm{~m} / \mathrm{s}, 8 \mathrm{~m} / \mathrm{s}$, and $9 \mathrm{~m} / \mathrm{s}$ exert the influences shown in Figure 14 on the air temperature at the outlet of the system during winter and summer.

For the operation conditions in winter, the average temperatures of the outlet of the systems under 7 air velocities are $9.3^{\circ} \mathrm{C}, 8.5^{\circ} \mathrm{C}, 7.7^{\circ} \mathrm{C}, 7.0^{\circ} \mathrm{C}, 6.4^{\circ} \mathrm{C}, 5.9^{\circ} \mathrm{C}$, and $5.4^{\circ} \mathrm{C}$, respectively. The air temperature at the outlet of the system decreases as the air velocity rises. In Figure 14(a), different air velocities in ducts exert a significant impact on the air temperature at the outlet. The faster the air in ducts flows, the less sharply the temperature rises. At the same time, the daily fluctuation amplitude of the air temperature at the outlet increases with the rise of air velocity. With the same heat transfer volume per unit area of ducts, the faster the air flows with the greater air volume, the smaller the difference between the temperature at the inlet and outlet will 


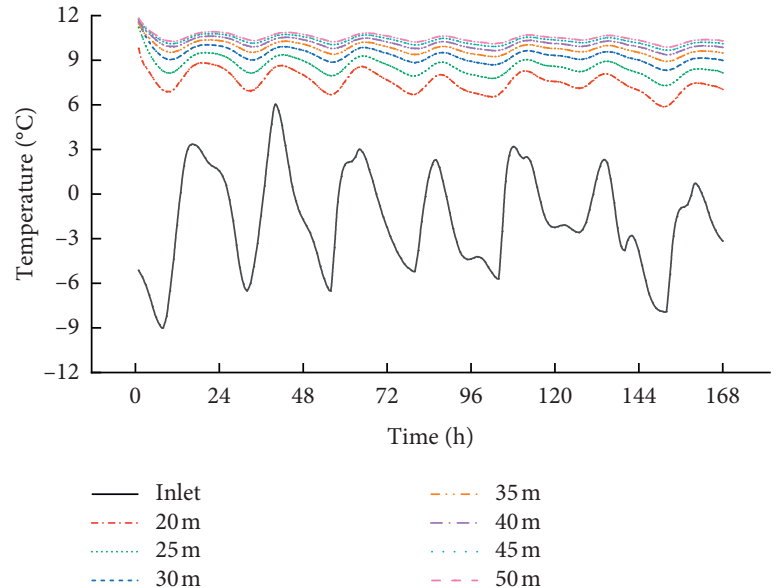

(a)

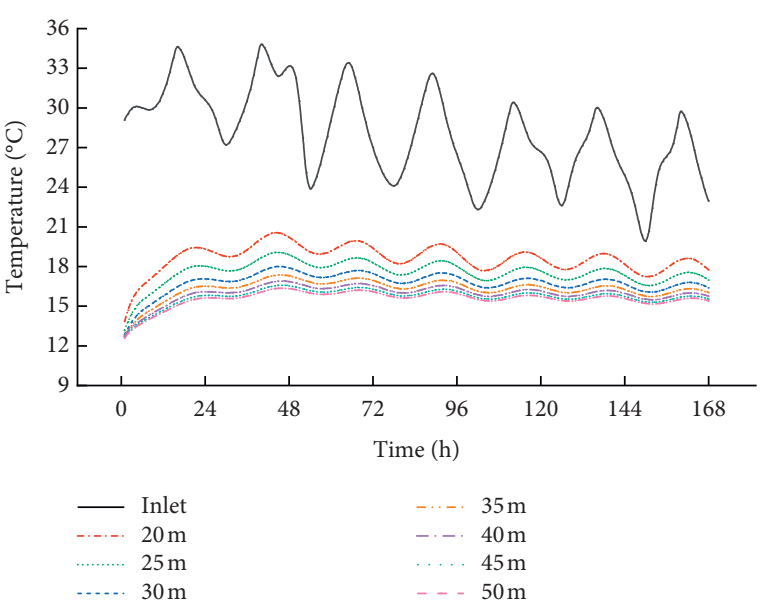

(b)

FIGURE 13: (a) The influence of buried depth of ducts on the outlet air temperature in winter. (b) The influence of buried depth of ducts on the outlet air temperature in summer.

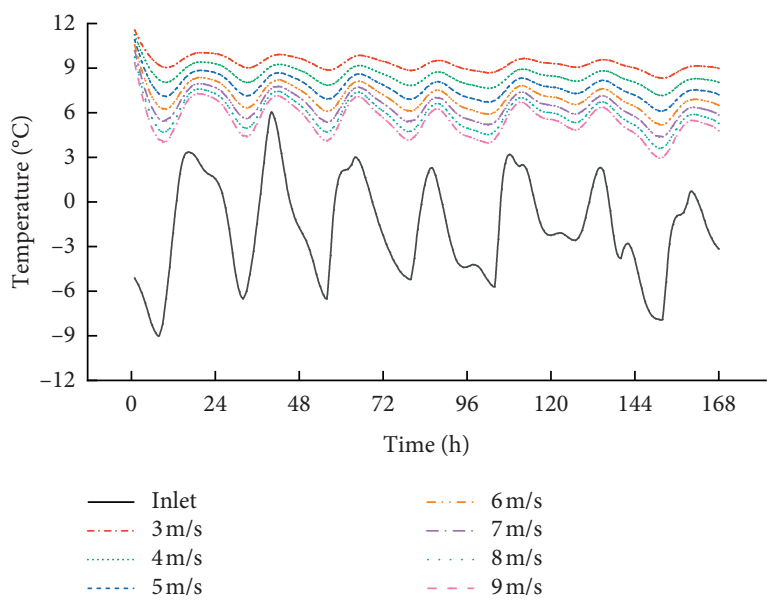

(a)

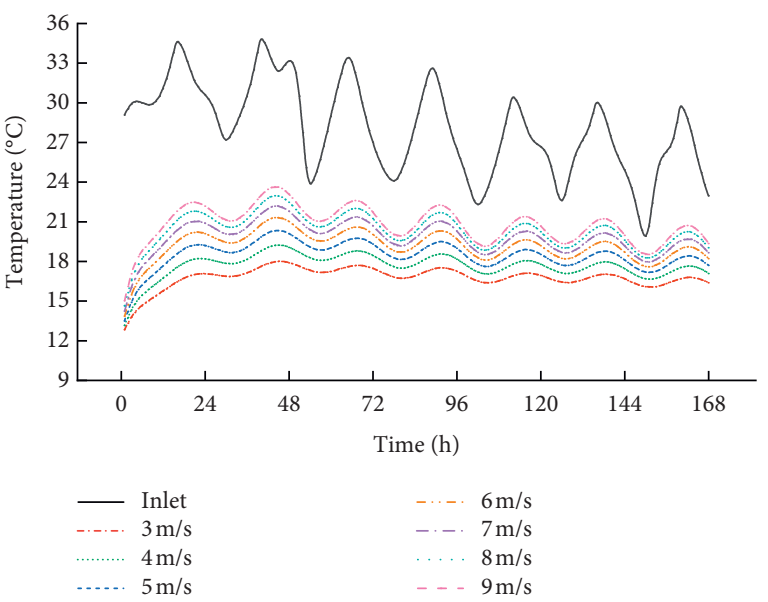

(b)

Figure 14: (a) The influence of air velocity in ducts on the outlet air temperature in winter. (b) The influence of air velocity in ducts on the outlet air temperature in summer.

be. The heat transfer between the air in ducts and soil is related with the duration for heat transfer. The increase of air velocity will shorten the time for heat transfer in ducts and reduce the air temperature at outlet. A slower air velocity will result in higher air temperature with less fluctuation at the outlet, thus improving the thermal comfort of fresh air supplied to rooms. However, as the air velocity decreases with the drop of air volume, the compatible number of vertical shafts will increase to meet the demands for fresh air volume with huger cost for investment. Therefore, it is necessary to achieve a sensible balance between the air temperature at the outlet and demands for air volume. It is advisable to keep the air velocity at $3-7 \mathrm{~m} / \mathrm{s}$ in actual engineering applications, so as to ensure the air volume of a single well as well as the air temperature at the outlet of the system.

The operation conditions in summer are shown in Figure 14(b), and the discussion will not be repeated here.

\subsection{Influences of Insulation Layers}

5.3.1. Influences of the Thickness of Insulation Layers. As mentioned earlier, laying insulating layers at the outlet of risers is conducive to the air temperature at the outlet. With other parameters unchanged, 5 thicknesses of insulation layers of different kinds including $0 \mathrm{~mm}, 10 \mathrm{~mm}, 20 \mathrm{~mm}, 30 \mathrm{~mm}$, and $40 \mathrm{~mm}$ exert the influences shown in Figure 15 on the air temperature at outlet of the system during winter and summer.

For the operation conditions in winter, the average temperatures at outlet of the systems with insulation layers of 5 different thicknesses are $8.7^{\circ} \mathrm{C}, 9.2^{\circ} \mathrm{C}, 9.5^{\circ} \mathrm{C}, 9.3^{\circ} \mathrm{C}$, and $9.0^{\circ} \mathrm{C}$, respectively. The air temperature at the outlet of the system rises at first and then drops with thicker insulation layers. The economic thickness of the insulation layer conforms to the basic theory of heat transfer. In Figure 15(a), insulation layers have an impact on the air temperature at 


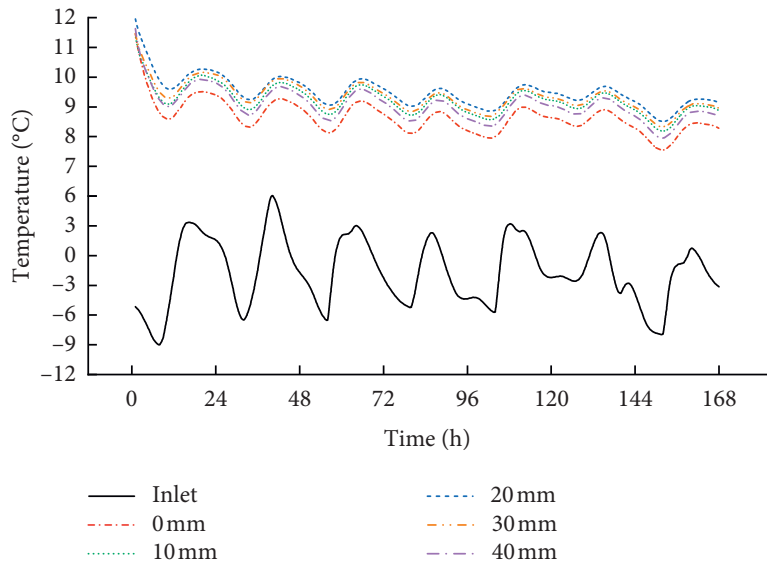

(a)

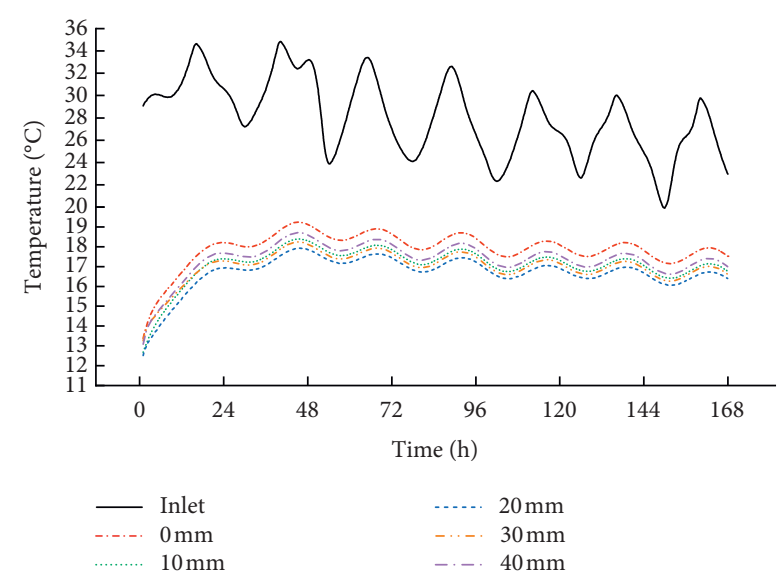

(b)

Figure 15: (a) The influence of the thickness of insulation layers on the outlet air temperature in winter. (b) The influence of the thickness of insulation layers on the outlet air temperature in summer.

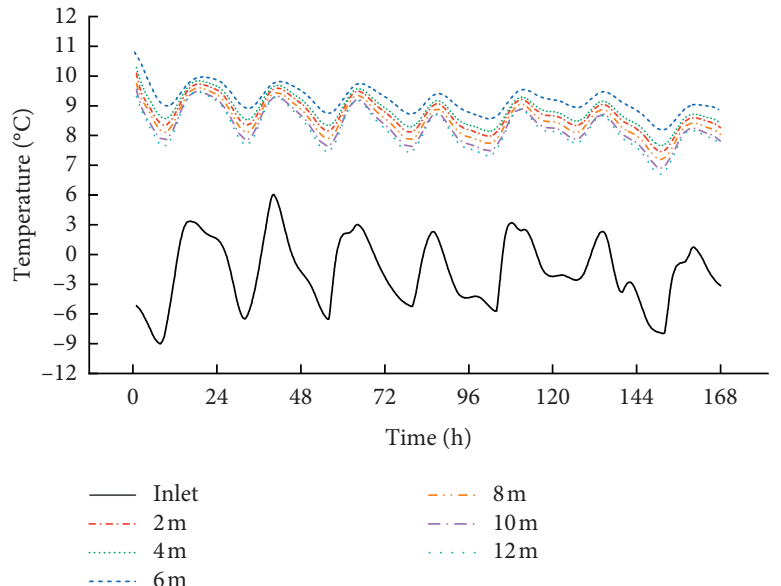

(a)

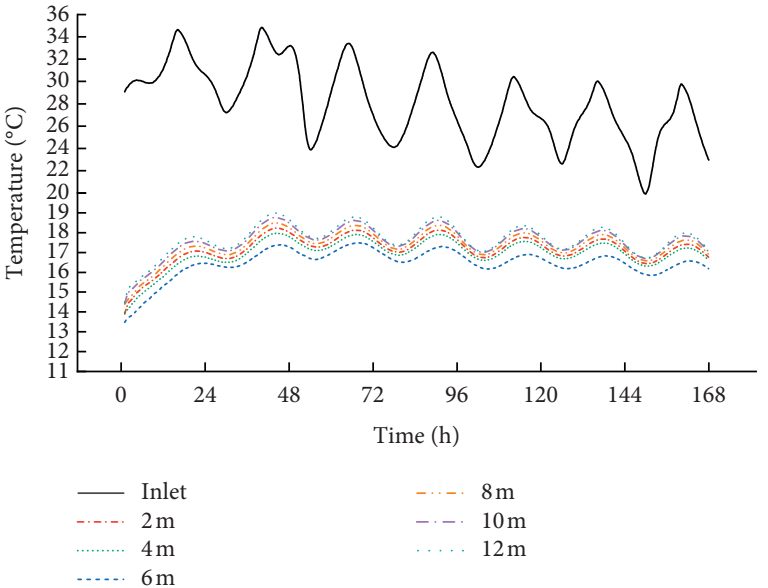

(b)

FIgURE 16: (a) The influence of the length of insulation layers on the outlet air temperature in winter. (b) The influence of the length of insulation layers on the outlet air temperature in summer.

the outlet of the system, not only reducing the impact of recooling of shallow soil near ground as well as the interference of heating or cooling caused by near pitch distance.

The operation conditions in summer are shown in Figure 15(b), and the discussion will not be repeated here.

5.3.2. Influences of the Length of Insulation Layers. With other parameters unchanged, 6 lengths of insulation layers of different kinds including $2 \mathrm{~m}, 4 \mathrm{~m}, 6 \mathrm{~m}, 8 \mathrm{~m}, 10 \mathrm{~m}$, and $12 \mathrm{~m}$ exert the influences shown in Figure 16 on the air temperature at outlet of the system during winter and summer.

For the operation conditions in winter, the average temperatures at the outlet of the systems with insulation layers of 7 different lengths are $8.7^{\circ} \mathrm{C}, 8.9^{\circ} \mathrm{C}, 9.2^{\circ} \mathrm{C}, 8.5^{\circ} \mathrm{C}$, $8.3^{\circ} \mathrm{C}$, and $8.2^{\circ} \mathrm{C}$, respectively. The air temperature at the outlet of the system rises at first and then drops with longer insulation layers. In Figure 16(a), different lengths of the insulation layer have a significant impact on the air temperature at the outlet, and there exists a relatively economical length of the insulation layer. If the length of insulation layers is too short, the air temperature in risers will be higher than that of surrounding shallow soil, which will cause the loss of air heat, affecting the air temperature at the outlet. If the length of insulation layers is too long, the air temperature in risers will be lower than that of the surrounding deep soil, affecting the further heating by soil. Consequently, it is advisable to choose the length of insulation layers at 2-4 $\mathrm{m}$ in actual engineering applications.

The operation conditions in summer are shown in Figure 16(b), and the discussion will not be repeated here.

5.4. Influences of Types of Soil. Soil of different types differs in moisture content, compaction level, density, thermal conductivity, specific heat capacity, and other parameters. The 
TABLE 3: Several common parameters of thermo-physical properties of soil.

\begin{tabular}{lcc}
\hline Type of soil & Density $\left(\mathrm{kg} \mathrm{m}^{-3}\right)$ & ${\text { Thermal conductivity }\left(\mathrm{W} \mathrm{m}^{-1} \mathrm{~K}^{-1}\right)}$ \\
\hline Dense clay (moisture of 15\%) & 1925 & 1.7 \\
Dense clay (moisture of 5\%) & 1925 & 1.2 \\
Light clay (moisture of 5\%) & 1285 & 0.7 \\
Tight sand (moisture of 5\%) & 1925 & 2.2 \\
Light sand (moisture of 5\%) & 1285 & 1.1 \\
\hline
\end{tabular}

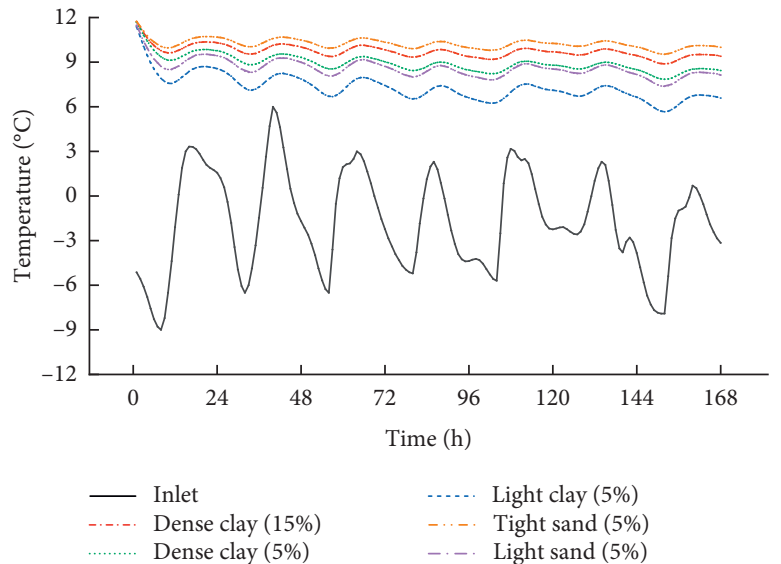

(a)

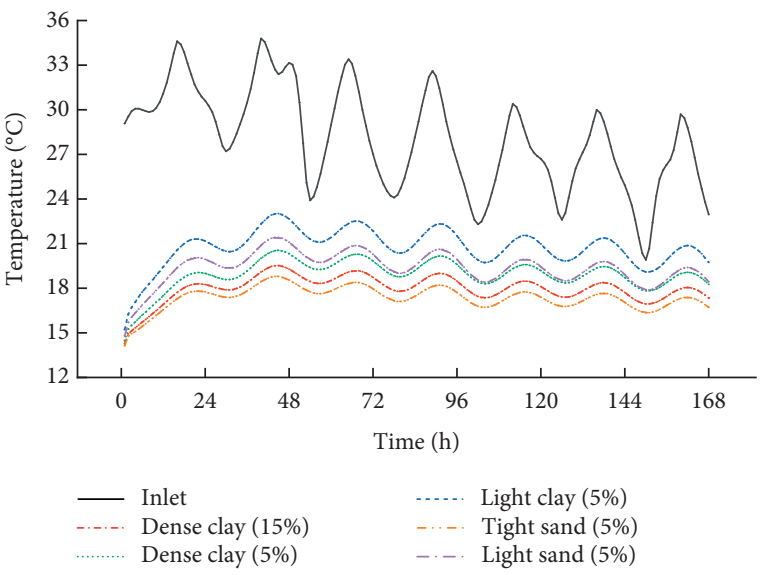

(b)

Figure 17: (a) The influence of types of soil on the outlet air temperature in winter. (b) The influence of types of soil on the outlet air temperature in summer.

physical properties of soil of 5 different types are shown in Table 3. With other parameters unchanged, soil of 5 types exerts the influences shown in Figure 17 on the air temperature of the outlet of the system during winter and summer.

The results showed that different soil types have a significant impact on the heat transfer performance of the VEAHE system. In Figure 17(a), for the operation conditions in winter, the larger the thermal conductivity of soil is, the higher the air temperature at outlet of the system will be. The more moisture soil of dense clay contains, the higher the air temperature at outlet of the system will be. With the same moisture content in soil, the more compact the soil is, the higher the air temperature at outlet of the system will be. Soil with higher thermal conductivity, larger moisture content, and higher compaction level could boost the air temperature at the outlet, the pattern that is consistent with the influences of physical parameters of soil on the EAHE system described in $[36,37]$.

The operation conditions in summer are shown in Figure 17(b), and the discussion will not be repeated here.

\section{Conclusion}

This paper proposes a new type of VEAHE system and develops its mathematical model. Compared with the traditional EAHE system, the advantage of the VEAHE system is that it increases the applicability of popularization and application in high-density building areas. It can avoid the impact of shallow soil temperature on its thermal performance caused by external environmental factors, and it also increases its applicability in areas prone to condensation such as high temperature and high humidity in summer. The results of numerical research on the VEAHE system can be summarized as follows:

(1) The VEAHE system boasts good thermal adaptability outdoor; the lower the outdoor temperature during winter is (or the higher the outdoor temperature during summer is), the more sharply the air temperature at outlet of the VEAHE system increases (or decreases) and the more productive the heat transfer of the system will be. The VEAHE system plays an efficient role in stabilizing and suppressing the fluctuation of outdoor fresh air temperature, and the effect becomes more and more obvious as time passes. Consequently, the system is more suitable for preheating by fresh air during winter in severe cold and cold areas, and it also plays an important role in precooling by fresh air during summer and protection against the cold during winter in hot-summer and warm-winter areas as well as hot-summer and cold-winter areas.

(2) In practical engineering applications, it is necessary to take into account the influences of different parameters on the thermal performance of the VEAHE system, and the demands for fresh air volume, air temperature requirements, and investment costs should be considered comprehensively. Therefore, it is recommended to use the PE or PVC material for 
the air duct. The depth of the air duct in cold areas is $30-40 \mathrm{~m}$ (in severe cold areas, it can be increased to $40-50 \mathrm{~m}$ ), and the diameter of the air duct is $150-250 \mathrm{~mm}$. When the air velocity of the system reaches $3-7 \mathrm{~m} / \mathrm{s}$, the air supply volume of a single shaft can reach $500-1200 \mathrm{~m}^{3} / \mathrm{h}$. In addition, laying an insulation layer can offset the impact on the thermal performance of the system due to too small pitch distance, and it is recommended that the thickness of the insulation layer is $20 \mathrm{~mm}$ and the length is $3 \mathrm{~m}$.

The research results are intended to provide guidance and basis for the construction and application of the VEAHE system and to increase the possibility of its further demonstration and application.

\section{Data Availability}

The data used to support the findings of the study are available from the corresponding author upon request.

\section{Conflicts of Interest}

The authors declare that they have no conflicts of interest.

\section{References}

[1] D. Yang, H. Wei, R. Shi, and J. Wang, "A demand-oriented approach for integrating earth-to-air heat exchangers into buildings for achieving year-round indoor thermal comfort," Energy Conversion and Management, vol. 182, pp. 95-107, 2019.

[2] R. Singh, R. L. Sawhney, I. J. Lazarus et al., "Recent advancements in earth air tunnel heat exchanger (EATHE) system for indoor thermal comfort application: a review," Renewable and Sustainable Energy Reviews, vol. 82, pp. 2162-2185, 2018.

[3] A. K. Kumar, A. G. Das, M. Rohit, B. Mayank, and J. D. Kamal, "A review on effect of geometrical, flow and soil properties on the performance of Earth air tunnel heat exchanger," Energy \& Buildings, vol. 176, pp. 120-138, 2018.

[4] H. Huanga, W. I. B. W. M. Nazib, Y. Yua, and Y. Wang, "Energy performance of a high-rise residential building retrofitted to passive building standard-a case study," Applied Thermal Engineering, vol. 181, Article ID 115902, 2020.

[5] A. Zajch, W. A. Gough, and G. Chiesa, "Earth-air heat exchanger geo-climatic suitability for projected climate change scenarios in the Americas," Sustainability, vol. 12, no. 24, Article ID 10613, 2020.

[6] J. M. ReyHernández, E. VelascoGómez, J. F. S. JoséAlonso, A. TejeroGonzález, and F. J. ReyMartínez, "Energy analysis at a near zero energy building: a case-study in Spain," Energies, vol. 11, no. 4, p. 857, 2018.

[7] Z. Liu, W. Xu, X. Zhai, C. Qian, and X. Chen, "Feasibility and performance study of the hybrid ground-source heat pump system for one office building in Chinese heating dominated areas," Renewable Energy, vol. 101, pp. 1131-1140, 2017.

[8] L. Qinggong, D. Zhenyu, and F. Yi, "Heat and mass transfer behavior prediction and thermal performance analysis of earth-to-air heat exchanger by finite volume method," Energies, vol. 11, no. 6, p. 1542, 2018.

[9] S. F. Ahmed, G. Liu, M. Mofijur, A. K. Azad, M. A. Hazrat, and Y.-M. Chu, "Physical and hybrid modelling techniques for earth-air heat exchangers in reducing building energy consumption: performance, applications, progress, and challenges," Solar Energy, vol. 216, pp. 274-294, 2021.

[10] M. Kaushal, "Geothermal cooling/heating using ground heat exchanger for various experimental and analytical studies: comprehensive review," Energy and Buildings, vol. 139, pp. 634-652, 2017.

[11] D. Yang, Y. Guo, and J. Zhang, "Evaluation of the thermal performance of an earth-to-air heat exchanger (EAHE) in a harmonic thermal environment," Energy Conversion and Management, vol. 109, pp. 184-194, 2016.

[12] S. F. Ahmed, M. M. K. Khan, M. T. O. Amanullah, M. G. Rasul, and N. M. S. Hassan, "Performance assessment of earth pipe cooling system for low energy buildings in a subtropical climate," Energy Conversion and Management, vol. 106, pp. 815-825, 2015.

[13] J. Ramalho, "Parameter analysis of Earth-air heat exchangers over multi-layered soils in South Brazil," Geothermics, vol. 93, no. 8, 2021.

[14] N. Sakhri, Y. Menni, and H. Ameur, "Experimental investigation of the performance of earth-to-air heat exchangers in arid environments," Journal of Arid Environments, vol. 180, Article ID 104215, 2020.

[15] N. Sakhri, M. Bensafi, Y. Menni, A. J. Chamkha, and N. Kaid, "Experimental study of an earth-to-air heat exchanger coupled to the solar chimney for heating and cooling applications in arid regions," Journal of Thermal Analysis and Calorimetry, no. 3, pp. 1-10, 2020.

[16] N. Sakhri, Y. Menni, and H. Ameur, "Impact of the environmental conditions on the efficiency of earth-to-air heat exchangers under various configurations," International Journal of Environmental Science and Technology, no. 2019, 2021.

[17] P. M. Congedo, C. Baglivo, S. Bonuso, and D. D’Agostino, "Numerical and experimental analysis of the energy performance of an air-source heat pump (ASHP) coupled with a horizontal earth-to-air heat exchanger (EAHX) in different climates," Geothermics, vol. 87, no. 4, Article ID 101845, 2020.

[18] H. Li, L. Ni, G. Liu, Z. Zhao, and Y. Yao, "Feasibility study on applications of an Earth-air Heat Exchanger (EAHE) for preheating fresh air in severe cold regions," Renewable Energy, vol. 133, pp. 1268-1284, 2019.

[19] K. T. Papakostas, A. Tsamitros, and G. Martinopoulos, "Validation of modified one-dimensional models simulating the thermal behavior of earth-to-air heat exchangers-comparative analysis of modelling and experimental results," Geothermics, vol. 82, pp. 1-314, 2019.

[20] A. Minaei and H. Safikhani, "A new transient analytical model for heat transfer of earth-to-air heat exchangers," Journal of Building Engineering, vol. 33, Article ID 101560, 2021.

[21] H. Su, X.-B. Liu, L. Ji, and J.-Y. Mu, "A numerical model of a deeply buried air-earth-tunnel heat exchanger," Energy \& Buildings, vol. 48, pp. 233-239, 2011.

[22] R. Kumar, S. C. Kaushik, and S. N. Garg, "Heating and cooling potential of an earth-to-air heat exchanger using artificial neural network," Renewable Energy, vol. 31, no. 8, pp. 1139-1155, 2006.

[23] R. Kumar, A. R. Sinha, B. K. Singh, and U. Modhukalya, “A design optimization tool of earth-to-air heat exchanger using a genetic algorithm," Renewable Energy, vol. 33, no. 10, pp. 2282-2288, 2008.

[24] M. Kepes Rodrigues, R. da Silva Brum, J. Vaz, L. A. Oliveira Rocha, E. Domingues dos Santos, and L. A. Isoldi, "Numerical investigation about the improvement of the thermal potential of an Earth-Air Heat Exchanger (EAHE) employing the 
constructal design method," Renewable Energy, vol. 80, pp. $538-551,2015$.

[25] Ł. Amanowicz and J. Wojtkowiak, "Thermal performance of multi-pipe earth-to-air heat exchangers considering the nonuniform distribution of air between parallel pipes," Geothermics, vol. 88, Article ID 101896, 2020.

[26] R. Singh, R. L. Sawhney, I. J. Lazarus, and V. V. N. Kishore, "Recent advancements in earth air tunnel heat exchanger (EATHE) system for indoor thermal comfort application: a review," Renewable \& Sustainable Energy Reviews, vol. 82, no. 3, pp. 2162-2185, 2018.

[27] L. Ozgener, "A review on the experimental and analytical analysis of earth to air heat exchanger (EAHE) systems in Turkey," Renewable and Sustainable Energy Reviews, vol. 15, no. 9, pp. 4483-4490, 2011.

[28] A. Mustafa Omer, "Ground-source heat pumps systems and applications," Renewable and Sustainable Energy Reviews, vol. 12, no. 2, pp. 344-371, 2008.

[29] D. Belatrache, S. Bentouba, and M. Bourouis, "Numerical analysis of earth air heat exchangers at operating conditions in arid climates," International Journal of Hydrogen Energy, vol. 42, pp. 8898-8904, 2016.

[30] S. K. Soni, M. Pandey, and V. N. Bartaria, "Energy metrics of a hybrid earth air heat exchanger system for summer cooling requirements," Energy and Buildings, vol. 129, pp. 1-8, 2016.

[31] P. M. Congedo, C. Lorusso, C. Baglivo, M. Milanese, and L. Raimondo, "Experimental validation of horizontal airground heat exchangers (HAGHE) for ventilation systems," Geothermics, vol. 80, pp. 78-85, 2019.

[32] W. Yang, M. Shi, G. Liu, and Z. Chen, "A two-region simulation model of vertical U-tube ground heat exchanger and its experimental verification," Applied Energy, vol. 86, no. 10, pp. 2005-2012, 2009.

[33] Z. Liu, Z. Yu, T. Yang et al., "Experimental investigation of a vertical earth-to-air heat exchanger system," Energy Conversion and Management, vol. 183, pp. 241-251, 2019.

[34] D. Chen and H. W. Chen, "Using the Köppen classification to quantify climate variation and change: an example for 1901-2010," Environmental Development, vol. 6, pp. 69-79, 2013.

[35] N. Sakhri, Y. Menni, and H. Ameur, "Effect of the pipe material and burying depth on the thermal efficiency of earthto-air heat exchangers," Case Studies in Chemical and Environmental Engineering, vol. 2, Article ID 100013, 2020.

[36] R. Misra, V. Bansal, G. D. Agrawal, J. Mathur, and T. Aseri, "Transient effect of soil thermal conductivity and duration of operation on performance of earth air tunnel heat exchanger," Applied Energy, vol. 103, pp. 1-11, 2013.

[37] N. A. S. Elminshawy, F. R. Siddiqui, Q. U. Farooq, and M. F. Addas, "Experimental investigation on the performance of earth-air pipe heat exchanger for different soil compaction levels," Applied Thermal Engineering, vol. 124, pp. 1319-1327, 2017. 